\author{
UNIVERSIDADE DE SÃO PAULO \\ FACULDADE DE ZOOTECNIA E ENGENHARIA DE ALIMENTOS
}

CAROLINA CIVE BARBOSA

Perfil de Inovação Farmacêutica Veterinária no Brasil

Pirassununga 
CAROLINA CIVE BARBOSA

\section{Perfil de Inovação Farmacêutica Veterinária no Brasil}

\section{Versão Corrigida}

Dissertação apresentada à Faculdade de Zootecnia e Engenharia de Alimentos da Universidade de São Paulo, como parte dos requisitos para a obtenção do Título de Mestre em Ciências.

Área de Concentração: Gestão e Inovação na Indústria Animal

Orientadora: Profa. Dra. Vera Letticie de Azevedo Ruiz 
Ficha catalográfica elaborada pelo Serviço de Biblioteca e Informação, FZEA/USP, com os dados fornecidos pelo(a) autor(a)

Cive Barbosa, Carolina

Perfil de inovação farmacêutica veterinária no Brasil / Carolina Cive Barbosa ; orientadora Vera Letticie de Azevedo Ruiz ; coorientador Celso da Costa Carrer. -- Pirassununga, 2017.

$64 \mathrm{f}$.

Dissertação (Mestrado - Programa de Pós-Graduação em Mestrado Profissional Gestảo e Inovaçào na Indústria Animal) -- Faculdade de Zootecnia e Engenharia de Alimentos, Universidade de São Paulo.

1. Inovação. 2. Saúde Animal. 3. Interaçăo universidade-empresa. I. de Azevedo Ruiz, Vera Letticie, orient. II. da Costa Carrer, Celso, coorient. III. Titulo. 


\title{
Perfil de Inovação Farmacêutica Veterinária no Brasil
}

\author{
Dissertação apresentada à Faculdade de \\ Zootecnia e Engenharia de Alimentos da \\ Universidade de São Paulo, como parte dos \\ requisitos para a obtenção do Título de \\ Mestre em Ciências. \\ Área de Concentração: Gestão e Inovação \\ na Indústria Animal \\ Orientador: Profa. Dra. Vera Letticie de \\ Azevedo Ruiz
}

Data de aprovação:

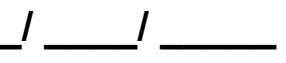

Banca Examinadora:

Profa. Dra. Vera Letticie de Azevedo Ruiz - Presidente da Banca Examinadora Faculdade de Zootecnia e Engenharia de Alimentos - Universidade de São Paulo Orientadora

Prof. Dr. Marcelo Machado De Luca de Oliveira Ribeiro

Faculdade de Zootecnia e Engenharia de Alimentos - Universidade de São Paulo

Prof. Dr. Osmar Gonçalves

Academia da Força Aérea (AFA) - Pirassununga 


\section{AGRADECIMENTOS}

À minha Família, pelo apoio, motivação e carinho.

Aos Amigos que compartilharam comigo os momentos de aprendizado $e$ acompanharam toda a minha trajetória na elaboração deste trabalho.

À minha Orientadora, Profa. Dra. Vera Letticie de Azevedo Ruiz, um agradecimento sincero por toda a paciência, compreensão e competência.

Ao Programa de Mestrado Profissional em Gestão e Inovação na Indústria Animal, representado pelo Prof. Dr. Celso Carrer.

À todos os Professores que fizeram parte desse caminho.

Ao meu Trabalho, às Empresas e Pessoas que encontrei em minha trajetória profissional que me apoiaram e permitiram mais essa oportunidade de conhecimento e crescimento.

Enfim, a todos aqueles que de uma maneira ou de outra contribuíram para a conclusão dessa etapa. 
"Jamais considere seus estudos como uma obrigação, mas como uma oportunidade invejável para aprender a conhecer a influência libertadora da beleza do reino do espírito, para seu próprio prazer pessoal e para o proveito da comunidade à qual seu futuro trabalho pertencer". (Albert Einstein) 


\section{RESUMO}

BARBOSA, C. C. Perfil de inovação farmacêutica veterinária no Brasil. 2017. 63

f. Dissertação (Mestrado) - Faculdade de Zootecnia e Engenharia de Alimentos, Universidade de São Paulo, Pirassununga, 2017.

A pesquisa objetivou avaliar o estado da arte da inovação no setor de saúde animal, tanto no sentido de saber como e o que está sendo produzido, quanto à verificação de possíveis interações com as universidades. Ainda, a ausência de trabalhos publicados avaliando os tipos de patentes depositadas, bem como os grupos de pesquisa que atuam, direta ou indiretamente, nesta área fortaleceu a necessidade de iniciar uma pesquisa nesse sentido. Assim, por meio do levantamento e classificação de patentes depositadas, no Brasil, por indústrias de saúde animal e universidades públicas bem com estudo dos grupos de pesquisa do CNPq, buscouse verificar o perfil de produção científico/tecnológico entre os dois atores principais (públicos e privados). Além disso, pontuou-se o que existe de demanda e oportunidade para inovação em saúde animal e fez-se uma primeira análise do nível de interação entre os grupos de pesquisa, que poderiam representar oportunidades de inovação, e empresas. Os resultados mostraram que o perfil de produção científica e tecnologia dos dois atores envolvidos, indústria e universidades, é distinto. Observa-se que as empresas de saúde animal apresentam maior número de depósitos de patente nas áreas de produtos biológicos e antiparasitários, enquanto as universidades apresentam pesquisas mais diluídas em temas de interesse para o setor de saúde animal, o que foi verificado tanto nas patentes depositadas quando na avaliação dos grupos de pesquisa. Ainda, verificou-se que, dos grupos avaliados, poucos declaram alguma parceria com instituições privadas. De uma forma geral, está sendo produzido conhecimento muito valioso nas universidades brasileiras que pode ser trabalhado em prol de colocar novas alternativas de medicamentos e terapias veterinárias. Neste contexto, acredita-se que a maior cooperação entre universidades e empresas da área de saúde animal poderá beneficiar o mercado e a sociedade com novas soluções.

Palavras-chave: Inovação. Saúde animal. Indústria farmacêutica veterinária. 


\begin{abstract}
BARBOSA, C. C. Veterinary pharmaceutical innovation profile in Brazil. 2017. 63

f. M.Sc. Dissertation - Faculdade de Zootecnia e Engenharia de Alimentos, Universidade de São Paulo, Pirassununga, 2017.
\end{abstract}

The goal of this research is to evaluate the state of art on innovation of the animal health sector, studying what has been produced and how, and the possible interactions with universities. The absence of published papers evaluating patents as well as the research groups that act, directly or indirectly, in the area of animal health have strengthened the need to initiate this research. Thus, through the survey and classification of patents registered in Brazil by animal health companies and public universities, as well as the evaluation of CNPq research groups, we sought to verify the scientific / technological production profile between the two main parties (public and private). In addition, this work pointed iut the existing demand and opportunity for innovation in animal health and an initial analysis of the level of interaction between research groups and companies was made. The results showed that the scientific technological production profile of the two parties is distinct. It was observed that animal health companies showed greater registration of patents on the areas of biological and antiparasitic products, while universities had patent registration more distributed on the topics of interest for animal health. These observations were true for both, registered patents and research groups do not state a partnership with a private company in the animal health industry. In general, information is created in Brazilian universities, and it can be used on the development for new alternatives for veterinary medicines and therapies. In conclusion, it is possible that greater cooperation between universities and animal health companies could benefit the market and the society with new solutions.

Keywords: Innovation. Animal health. Veterinary pharmaceutical industry. 


\section{SUMÁRIO}

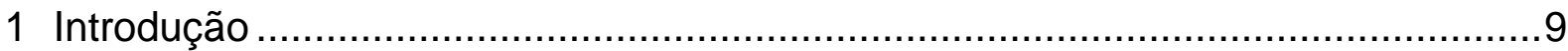

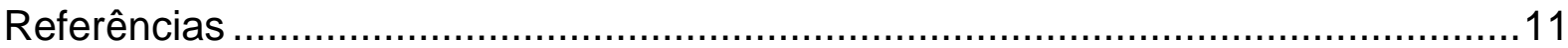

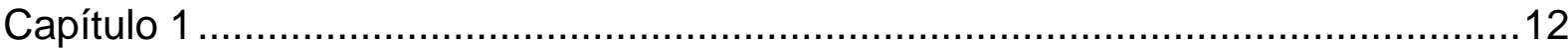

Inovação farmacêutica veterinária no Brasil................................................13

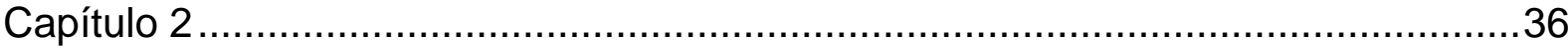

Análise da interação entre a indústria farmacêutica veterinária e os grupos de pesquisa no contexto de inovação .......................................................... 37

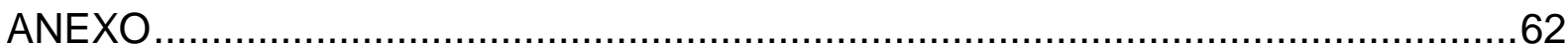




\section{Introdução}

Nos últimos anos, o segmento das indústrias farmacêuticas veterinárias apresentou crescimento significativo. O mercado mundial atingiu faturamento de US\$22,5 bilhões em 2012, com crescimento médio de $8 \%$ ao ano desde 2002 . Em 2015 o faturamento mundial em saúde animal foi US\$23,9 bilhões. Esse crescimento tem sido estimulado principalmente pela venda de produtos destinados ao uso em pequenos animais (pet) que, atualmente, corresponde a aproximadamente $40 \%$ da demanda do mercado mundial (SINDAN, 2015; Banco Nacional de Desenvolvimento Econômico e Social - BNDES, 2013)

No Brasil, o faturamento da indústria de saúde animal foi US $\$ 4,9$ bilhões no ano de 2015. O principal setor que alavanca tal crescimento é o dos produtos destinados aos animais de produção (que correspondem a $81 \%$ do mercado). Dentre as classes de produtos, os maiores faturamentos se dão para os produtos biológicos que têm sido buscados pelo fortalecimento das campanhas nacionais de vacinação e maior conscientização em relação ao manejo sanitários dos animais; e para os produtos antiparasitários, bastante demandados na bovinocultura (SINDAN, 2015; BNDES, 2013).

A situação do mercado nacional pode ser mais favorável quando consideramos um possível aumento no mercado pet. Segundo dados da Associação Brasileira da Indústria e de Produtos para Animais de Companhia (ABINPET, 2013), o número de animais de companhia aumenta cerca de $5 \%$ ao ano e, com a tendência da menor natalidade na população humana, esses números podem ser ainda maiores futuramente. Ainda, deve ser considerado que o mercado de animais de produção continua promissor com a maior tecnificação das unidades produtoras e conhecimento das pessoas quanto à saúde animal quando se trata de produção.

Neste contexto, as inovações no setor da indústria veterinária se tornam fundamentais, uma vez que o mercado é competitivo e os consumidores passam a exigir cada vez mais dos produtos e serviços ofertados. Para se manterem competitivas, as empresas terão que apresentar estratégias para melhoria da gestão de Pesquisa, Desenvolvimento e Inovação (PD\&I), como instrumento de rotina em seu portfólio de produtos e serviços.

Neste contexto esta dissertação foi desenvolvida no formato de artigos, apresentados em dois capítulos. 
O primeiro artigo foi desenvolvido no sentido de trazer um panorama atual do mercado de saúde animal no Brasil, com base em pesquisa bibliográfica e breve levantamento sobre inovação no setor, trazendo informações das indústrias farmacêuticas veterinárias, patentes e grupos de pesquisa com temas ligados à saúde animal.

O segundo artigo analisou patentes depositadas no Brasil por empresas de saúde animal e universidades, além de grupos de pesquisa nas áreas de interesse para a saúde animal. Buscou entender se o perfil de produção científica e tecnológica é semelhante entre indústria e Universidade, bem como fazer uma busca inicial de parcerias traçadas entre esses dois atores. 


\section{Referências}

ASSOCIAÇÃO BRASILEIRA DA INDÚSTRIA E DE PRODUTOS PARA ANIMAIS DE COMPANHIA - ABINPET. População de pets cresce $5 \%$ ao ano e Brasil é quarto no ranking mundial. 2013. Disponível em:<http://abinpet.org.br/site/portal-mfpopulacao-de-pets-cresce-5-ao-ano-e-brasil-e-quarto-no-ranking-mundial/>. Acesso em: 10 de junho de 2014.

BANCO NACIONAL DE DESENVOLVIMENTO ECONÔMICO E SOCIAL - BNDES. Informe setorial: área industrial, Brasília, n. 27, p. 1-6, nov. 2013.

SINDICATO NACIONAL DA INDÚSTRIA DE PRODUTOS PARA SAÚDE ANIMA SINDAN. Mercado. 2015.Disponível em:

$<\mathrm{http}: / /$ www.sindan.org.br/sd/base. aspx? controle=8>. Acesso em: 12 jan. 2015. 


\section{Capítulo 1}

Aguardando parecer do editor, artigo encaminhado para publicação na Revista do Conselho Federal de Medicina Veterinária - CFMV. 


\title{
Inovação Farmacêutica Veterinária no Brasil
}

\section{RESUMO}

A medicina veterinária, dentre outras funções, é responsável pela manutenção da sanidade e produtividade dos animais de produção, bem como na promoção de saúde e bem estar das espécies domésticas. Exerce papel importante em saúde pública, atuando no controle de zoonoses e na produção de alimentos de origem animal seguros. A indústria farmacêutica veterinária está inserida em todo este contexto e fornece ferramentas para que tais funções sejam exercidas. Este mercado vem apresentando, ano a ano, maior faturamento, inovações de portfólio e novos entrantes. Este trabalho objetivou verificar quem são os atores desta indústria, como ocorre a inovação neste setor e levantar algumas oportunidades de inovação bem como fontes de fomento para inovação. Assim foram expostos aspectos do mercado mundial e nacional, descrição do panorama das indústrias farmacêuticas veterinárias, bem como apresentação das principais atuantes. É abordado também o tema de inovação e como ela ocorre neste setor (oportunidades, desafios e estratégias). Além disso, são apresentados levantamentos de patentes e grupos de pesquisa como oportunidades de inovação e descritas algumas fontes de fomento por parte do Estado para auxiliar no processo de inovação.

Palavras-chave: Indústria farmacêutica veterinária. Inovação. Universidades.

\section{Veterinary Pharmaceutical Innovation in Brazil}

\begin{abstract}
Veterinary Medicine is responsible for maintaining the sanity and productivity of food animals, as well as promoting health and welfare for domestic species. It plays an important role in public health, acting on disease control and food safety. The veterinary pharmaceutical industry is embedded in this context and provides tools for such roles to be executed. This market has been presenting, year by year, sales improvements, innovation on portfolios and new entrants. This paper aimed to verify who are the actors on this industry, how innovation occurs in this sector and raise up some opportunities for innovation, as well as public resources for innovation. Thus,
\end{abstract}


this research embraces international and national market aspects, veterinary pharmaceutical industries characteristics, as well as presentation of the main companies. It also addresses innovation issues and how it occurs in this sector (opportunities, challenges and strategies). In addition, patent surveys and research groups are presented as innovation opportunities and some public resources to innovation are summarized.

Keywords: Veterinary pharmaceutical industry. Innovation. Universities.

\section{Introdução}

A cadeia produtiva da indústria farmacêutica veterinária é muito semelhante à farmacêutica da saúde humana, pois os dois setores compartilham muitos fármacos na sua terapêutica. Assim, várias empresas de produtos para saúde animal são também da área humana, por facilitar a diluição dos elevados custos de Pesquisa e Desenvolvimento (P\&D), aumentar a diversificação das atividades e levantar lucros com as vendas dos produtos veterinários para reinvestir nesta área e também na área humana (CAPANEMA et al., 2007; AHMED; KASRAIAN, 2002).

A indústria veterinária caracteriza-se por dois modelos de empresas: grandes empresas internacionais químico-farmacêuticas, com atuação global, líderes no processo de inovação e empresas nacionais de menor porte. Essas últimas são especializadas nas necessidades locais e nichos de mercado (CAPANEMA et al., 2007).

O mercado de saúde animal é dominado por empresas multinacionais com sede em países desenvolvidos, como Estados Unidos, França e Alemanha. Observa-se que, apenas quatro das dez maiores atuam exclusivamente no mercado de saúde animal (Zoetis, Idexx, Virbac e Ceva). As demais são divisões de saúde animal de grandes conglomerados farmacêuticos com foco em saúde humana (BNDES, 2013).

Segundo Capanema et al. (2007) a expansão do mercado de saúde animal é crescente e pode ser atribuída a quatro fatores: (1) crescimento da população de animais de companhia; (2) a continuidade da ameaça de doenças animais; (3) o aumento do interesse público sobre a segurança alimentar e consequente aumento do rigor do arcabouço regulatório; (4) o banimento do uso de antimicrobianos como 
promotores de crescimento animal na Comunidade Europeia que gera perdas expressivas imediatas de faturamento, além de comprometer e reduzir o ciclo de vida de outros produtos. Em médio prazo, isto reforça a necessidade de portfólios alternativos de produtos para animais produtores de alimento, e neste contexto do mercado nacional, a inovação no setor da indústria farmacêutica veterinária se faz necessária.

A tabela 1 apresenta o ranking mundial de indústrias farmacêuticas veterinárias em 2014, considerando seus faturamentos em bilhões de dólares.

Tabela 1 - Ranking mundial das indústrias farmacêuticas veterinárias.

\begin{tabular}{|c|c|c|c|c|}
\hline Colocação & Empresa & Origem & $\begin{array}{c}\text { Faturamento } \\
\text { (US\$ } \\
\text { bilhões) }\end{array}$ & $\begin{array}{c}\text { Participação } \\
\text { (\%) }\end{array}$ \\
\hline 1 & Zoetis & EUA & 4,79 & 20,02 \\
\hline 2 & $\begin{array}{l}\text { MSD Animal } \\
\text { Health }\end{array}$ & EUA & 3,45 & 14,45 \\
\hline 3 & $\begin{array}{l}\text { Merial } \\
\text { Elanco }\end{array}$ & França & 2,76 & 11,55 \\
\hline 4 & $\begin{array}{l}\text { Animal } \\
\text { Health } \\
\text { Bayer }\end{array}$ & EUA & 2,35 & 9,82 \\
\hline 5 & $\begin{array}{l}\text { Animal } \\
\text { Health }\end{array}$ & Alemanha & 1,75 & 7,33 \\
\hline 6 & $\begin{array}{l}\text { Boehringer } \\
\text { Ingelheim }\end{array}$ & Alemanha & 1,50 & 6,28 \\
\hline 7 & $\begin{array}{c}\text { Idexx } \\
\text { Laboratories }\end{array}$ & EUA & 1,36 & 5,71 \\
\hline 8 & Virbac & França & 1,03 & 4,30 \\
\hline 9 & $\begin{array}{c}\text { Ceva Santé } \\
\text { Animale } \\
\text { Phibro }\end{array}$ & França & 1,02 & 4,26 \\
\hline 10 & $\begin{array}{l}\text { Animal } \\
\text { Health }\end{array}$ & EUA & 0,63 & 2,65 \\
\hline \multicolumn{3}{|c|}{ Total 10 maiores } & 20,64 & 86,37 \\
\hline \multicolumn{3}{|c|}{ Total do mercado } & 23,9 & 100 \\
\hline
\end{tabular}

Fonte: ANIMALL PHARM. Animal health industry rankings 2014: are the leaders better together or stronger apart? 2015. Disponível em: <https://www.agra-net.com/agra/animal-pharm/analysis/animalhealth-industry-rankings-2014-are-the-leaders-better-together-or-stronger-apart-478068.htm>. Acesso em: 14 dez. 2016; SINDICATO NACIONAL DA INDÚSTRIA DE PRODUTOS PARA SAÚDE ANIMAL - SINDAN. Mercado. Disponível em: <http://www.sindan.org.br/sd/base.aspx?controle=8>. Acesso em: 12 jan. 2015.

$\mathrm{Na}$ tabela 2, podemos observar o ranking nacional das indústrias farmacêuticas veterinárias considerando o faturamento em milhões de Reais no ano de 2012. 
Tabela 2 - Ranking nacional das indústrias farmacêuticas de saúde animal por faturamento.

\begin{tabular}{|c|c|c|c|c|}
\hline Colocação & Empresa & Origem & $\begin{array}{l}\text { Faturamento } \\
\text { (R\$ milhões) }\end{array}$ & $\begin{array}{c}\text { Participação } \\
(\%)\end{array}$ \\
\hline 1 & \multirow{3}{*}{$\begin{array}{c}\text { Zoetis } \\
\text { MSD Animal } \\
\text { Health } \\
\text { Merial }\end{array}$} & EUA & 592 & 16,2 \\
\hline 2 & & EUA & 500 & 13,7 \\
\hline 3 & & França & 450 & 12,3 \\
\hline 4 & \multirow{2}{*}{$\begin{array}{l}\text { Ourofino } \\
\text { Agronegócio } \\
\text { Vallée } \\
\text { Bayer }\end{array}$} & Brasil & 359 & 9,8 \\
\hline 5 & & Brasil & 200 & 5,5 \\
\hline 6 & $\begin{array}{l}\text { Animal } \\
\text { Health }\end{array}$ & Alemanha & 150 & 4,1 \\
\hline 7 & $\begin{array}{l}\text { Hertape } \\
\text { Calier } \\
\text { Novartis }\end{array}$ & Brasil & 140 & 3,8 \\
\hline 8 & $\begin{array}{l}\text { Animal } \\
\text { Health }\end{array}$ & Suíça & 137 & 3,7 \\
\hline \multicolumn{3}{|c|}{ Total 8 maiores } & 2.528 & 69,1 \\
\hline \multicolumn{3}{|c|}{ Total do mercado } & 3.660 & 100,0 \\
\hline
\end{tabular}

Fonte: Adaptado de BANCO NACIONAL DE DESENVOLVIMENTO ECONÔMICO E SOCIAL BNDES. Informe Setorial: área industrial, Brasília, n. 27, p.1-6, nov. 2013

Nos últimos anos, a indústria farmacêutica veterinária apresentou crescimento significante. O mercado mundial apresentou faturamento de US\$23,9 bilhões em 2014, com crescimento nominal de 4\%. Esse crescimento tem sido estimulado principalmente pela venda de produtos destinados ao uso em pequenos animais (pet) que, atualmente, corresponde a aproximadamente $40 \%$ da demanda do mercado mundial (Vetnosis apud Sindan, 2015). No Brasil, no período de 2008 a 2015 foi verificado aumento nominal de aproximadamente 97\% neste seguimento, culminando com uma receita de $\mathrm{R} \$ 4.961$ milhões no ano de 2015. As espécies com maior demanda por produtos veterinários no ano de 2015 foram os ruminantes (53,9\%), seguido por cães e gatos (16,4\%), aves (15,1\%), suínos (12,3\%) e equinos e outras espécies (2,8\%). Quanto às classes de produtos veterinários para saúde animal, o (SINDAN, 2015) informa que cerca de 50\% do faturamento em 2015 foi fruto da venda de produtos biológicos (produtos terapêuticos obtidos com base em organismos vivos ou derivados destes, como soros, vacinas, antitoxinas e antígenos (CAPANEMA et al., 2007) e antiparasitários. A situação do mercado nacional pode ser mais favorável quando se considera um possível aumento no mercado pet. Segundo dados da Associação Brasileira da Indústria e de Produtos para Animais de Companhia (ABINPET, 2013) o número de animais de companhia aumenta cerca de $5 \%$ ao ano. Ainda, deve ser considerado que o mercado de animais de produção 
continua promissor com a maior tecnificação das unidades produtoras e aumento do conhecimento das pessoas quanto à saúde animal quando se trata de produção.

Segundo Paco Ortiz (2014), diretor-presidente da Zoetis Brasil em entrevista para a Associação Nacional de Criadores e Pesquisadores em 06 de novembro de 2014:

"O país é uma superpotência no setor agropecuário e um mercadochave para os objetivos de negócio da companhia. Para que possamos manter a nossa liderança e crescimento rentável, vamos investir ainda mais em nosso diferencial de mercado, portfólio completo e atuação em campo, e direcionar os nossos recursos para maximizar esses resultados."

Neste contexto, as inovações no setor da indústria veterinária se tornam fundamentais, uma vez que o mercado é competitivo e os consumidores passam a exigir cada vez mais dos produtos e serviços ofertados. Para manterem-se competitivas, as empresas terão que apresentar estratégias para melhoria da gestão de Pesquisa, Desenvolvimento e Inovação (PD\&l) e de uma vez por todas enfocar a inovação como instrumento de rotina em seu portfólio de produtos e serviços.

\section{0 que é inovação e de que forma ela pode ocorrer na indústria farmacêutica veterinária?}

Segundo (OECD, 2005) a Inovação pode ser definida como:

“... uma implementação de um produto (bem ou serviço) novo ou significativamente melhorado, ou um processo, ou um novo método de marketing, ou um novo método organizacional nas práticas de negócios, na organização do local de trabalho ou nas relações externas".

De acordo com a "Lei da Inovação", n’ 10.973 de 02/12/2004 (BRASIL, 2004), inovação é a introdução de novidade ou aperfeiçoamento no ambiente produtivo ou social que resulte em novos produtos, processos ou serviços.

Dentre os tipos de inovação, a inovação na indústria farmacêutica pode ocorrer de forma incremental, quando apresenta pequenas modificações ou adaptações em um produto ou processo já existente. Tais adequações não acarretam mudanças enfáticas nos procedimentos em vigor e não apresentam novidades terapêuticas. Já quando ocorre o desenvolvimento de uma nova molécula a qual pode levar a um novo medicamento, possível de ser patenteada a inovação 
pode caracterizar-se como radical ou de inovação de ruptura (KAMIMURA; CORNETTA, 2011).

Para Santoro (2000), a inovação incremental ou de ruptura, se dá quando o produto é introduzido no mercado, sendo que o processo de P\&D conduz à inovação, mas não corresponde a ela propriamente dita. Assim, apresenta uma classificação para a inovação de produtos farmacêuticos levando em consideração a rota de síntese química: a) identificação (screening) de nova substância ativa (novo princípio ativo) - descoberta; b) obtenção de nova molécula derivada de análises estrutura-atividade (novo fármaco) - invenção; c) nova formulação farmacêutica/composto (novo medicamento) - inovação radical; d) desenvolvimento de novo princípio ativo ao redor de estrutura química já conhecida (me too) inovação incremental; e) novas indicações de uso para entidades químicas já conhecidas (novo alvo) - inovação incremental; f) novas associações de formulações- inovação incremental; g) duplicação de produtos já comercializados (genérico ou similar) - estes, para serem considerados inovação, precisam agregar valor ao produto já existente (uma formulação que melhore absorção do produto no organismo, por exemplo).

Uma forma de a indústria proteger suas invenções é fazer o patenteamento delas. A patente constitui um título temporário de propriedade com objetivo de proteger novos produtos, processos ou aperfeiçoamentos que tenham aplicação industrial e apresentem uma solução tecnológica para um problema específico (SOUZA; MURAKAWA, 2014).

Considerando o ranking das maiores empresas farmacêuticas veterinárias atuantes no mercado nacional em 2012, a tabela 3 apresenta o número de patentes depositadas no Brasil, considerando diferentes classificações de produtos. Somada a estas informações, a tabela 4 apresenta o número de patentes depositadas por tais empresas em nível global. 
Tabela 3 - Número de patentes depositadas no Brasil das empresas farmacêuticas veterinárias com maior atuação no país (período de 10 anos).

\begin{tabular}{lcccccc|c}
\hline \multicolumn{1}{c}{ Classe } & Zoetis & Merial & Ourofino & Vallée & Bayer & Elanco & Total/Classe \\
\hline Aditivo & 1 & 0 & 1 & 1 & 1 & 0 & 4 \\
Anestésico & 0 & 0 & 1 & 0 & 0 & 0 & 1 \\
Antimicrobiano & 8 & 3 & 5 & 0 & 4 & 2 & 22 \\
Antinflamatório & 0 & 0 & 1 & 0 & 0 & 0 & 1 \\
Antiparasitário & 24 & 32 & 1 & 0 & 12 & 0 & 69 \\
Biológicos & 25 & 31 & 3 & 1 & 1 & 0 & 61 \\
Liberação Controlada & 0 & 1 & 0 & 0 & 7 & 0 & 8 \\
Nanotecnologia & 0 & 0 & 0 & 0 & 0 & 0 & 0 \\
Outros & 6 & 9 & 2 & 1 & 10 & 0 & 28 \\
Reprodução & 0 & 0 & 1 & 0 & 0 & 0 & 1 \\
\hline \multicolumn{1}{c}{ Total } & 64 & 76 & 15 & 3 & 35 & 2 & 195 \\
\hline
\end{tabular}

Fonte: INSTITUTO NACIONAL DA PROPRIEDADE INDUSTRIAL - INPI. Base de patentes.

Disponível em:<https://gru.inpi.gov.br/pePl/jsp/patentes/PatenteSearchBasico.jsp>. Acesso em: 15 dez. 2016.

Tabela 4 - Número de patentes das maiores empresas farmacêuticas veterinárias.

\begin{tabular}{lcc}
\hline Empresa & $\begin{array}{c}\text { Número de } \\
\text { Patentes }\end{array}$ & Período \\
\hline Zoetis & 444 & 2003-atual \\
Merial & 2056 & 1990-atual \\
Ourofino & 39 & 1998-atual \\
Vallée & 10 & 1996-atual \\
Bayer & 491 & 1998-atual \\
Elanco & 23 & 2006-atual \\
\hline \multicolumn{1}{c}{ Total } & 3063 &
\end{tabular}

Fonte: ANIMAL PHARM. Patent archive. Disponível em:<https://www.agra-net.com/agra/animalpharm/data/patent-archive/>. Acesso em: 14 dez. 2016.; INSTITUTO NACIONAL DA PROPRIEDADE INDUSTRIAL - INPI. Base de patentes. Disponível em:<https://gru.inpi.gov.br/pePl/jsp/patentes/PatenteSearchBasico.jsp>. Acesso em: 15 dez. 2016.

Pelas informações de patentes descritas nas tabelas 3 e 4 é possível afirmar dois aspectos relacionados à inovação do setor farmacêutico veterinário no Brasil. $O$ primeiro diz respeito à diferença existente no número de patentes depositadas por indústrias multinacionais e nacionais, o que destaca a maior capacidade inovativa das multinacionais. O segundo aspecto é o grande número de patentes de antiparasitários e produtos biológicos depositadas no Brasil, o que corrobora com os dados disponibilizados pelo Sindan, nos quais se observa maior participação dessas duas classes de produtos no mercado nacional. 
Contudo, novidade por si só não implica inovação. Ela deve ser combinada com a disposição dos consumidores em pagar por isso. Assim, sob condições normais de mercado, o consumidor é o árbitro final do valor. Baseado nisso, alguns atributos como ganhos em saúde e conveniência para o paciente são importantes para o desenvolvimento da inovação (MESTRE-FERRANDIZ; MORDOH; SUSSEX, 2012). Na indústria veterinária, outro atributo de grande importância são os resíduos de medicamentos quando se consideram os animais de produção (SILVA, 2009).

Ao falar em ganhos na saúde Mestre-Ferrandiz, Mordoh e Sussex (2012) referem-se à otimização da terapêutica de uma doença, melhora na qualidade de vida; menor tempo de recuperação; baixa interação medicamentosa com outros ativos; menores efeitos colaterais melhorando a tolerância e adesão ao tratamento. Os autores descrevem a necessidade de medicamentos que sejam mais práticos resultando em maior adesão ao tratamento. $O$ aumento na praticidade do medicamento influencia no aumento da disposição dos pacientes em pagar pela inovação, que apesar de ter custo mais alto poderá apresentar melhores resultados em decorrência da maior adesão. No setor farmacêutico veterinário esse é um dos fatores avaliados pelos donos de pets na decisão de compra, os donos procuram por medicamentos mais fáceis de administrar e que sejam mais palatáveis aos pets. mesmo vale para os animais de grande porte, como os equinos. Para bovinos, a conveniência reside sobre a facilidade e agilidade de administração do medicamento no rebanho (AHMED; KASRAIAN, 2002).

Os atributos referentes aos resíduos são específicos para o setor farmacêutico veterinário, pois as drogas administradas aos animais de produção devem possuir a premissa de serem eliminadas no menor período de tempo possível para não comprometer a produção de alimentos destinados ao consumo humano como carne, leite e ovos (SILVA, 2009). Este é um campo que gera grande competitividade entre as empresas de saúde animal e produtos inovadores como, por exemplo, novos antiparasitários com baixo período de carência ou até mesmo sem necessidade da realização de um período de carência podem representar ganhos expressivos para a empresa tanto em valor quanto em posição de mercado.

No segmento de animais criados para consumo, as inovações em produto são mais sensíveis à disposição do criador em gastar com a sanidade do rebanho uma vez que não há relação de afeto determinando o valor do animal. Assim, as inovações são, em geral, de menor custo e que possuam maior custo-benefício para 
o criador estimulando sua disposição em investir em produtos novos (SILVA, 2009). Nesse sentido, a inovação pode ocorrer, por exemplo, no processo de produção de um determinado produto de forma a otimizar a produção e diminuir gastos, o que pode impactar na margem de lucro do produtor.

Algumas oportunidades são fontes para inovação na indústria farmacêutica veterinária, como o desenvolvimento de produtos com sistema de administração transdérmico (ARYA et al., 2016; ALEXANDER et al., 2012), a existência de resistência antimicrobiana (KOHL et al., 2016) que direciona para o desenvolvimento de princípios ativos não compartilhados com a medicina humana e tratamentos preventivos como as vacinas (COMISSÃO EUROPÉIA, 2011), a resistência parasitária às moléculas existentes no mercado como as avermectinas (HOLSBACK et al., 2015; NEVES, 2014; CRUZ, 2013), piretróides (MATIAS et al., 2011), organofosforados (MENDES et al., 2011), o que gera demanda por novos produtos. Outras fontes de inovação são ainda o desenvolvimento de nanotecnologia (LIMA, 2016), produção de implantes para liberação de drogas e vacinas in situ (MCKAY et al., 2017; THAKUR; McMILLAN; JONES, 2014), fármacos para distúrbios comportamentais em animais de companhia (PEREIRA et al., 2016), fármacos para tratar câncer, produtos naturais, doenças emergentes e zoonoses (SILVA, 2009).

\section{Desafios ao processo de inovação na indústria farmacêutica veterinária}

O desenvolvimento de medicamentos veterinários lida com muitos desafios além da variedade dentro de cada espécie. Os principais desafios são (SILVA, 2009):

- a enorme diversidade em espécies: tamanho, comportamento, necessidades metabólicas, e expectativa de vida, diferenças nos perfis farmacocinéticos e de toxicidade entre espécies e raças distintas;

- amplo espectro de agentes patogênicos que produzem diferentes manifestações de doenças sobre diferentes condições e variações sazonais;

- diferentes práticas de criação animal, que incluem uma variedade de cenários nos quais os animais são mantidos - estendendo-se desde animais de companhia em casa até grandes rebanhos; 
- restrições financeiras, associadas ao valor do animal a ser tratado. O custo tem grande impacto na decisão de compra no setor de animais de produção, sendo crítico, por exemplo, no mercado de vacinas. Já para o setor pet, existe também criticidade de custo, mas com menor impacto. No setor pet, este fato estará relacionado ao grau de afetividade entre proprietário e animal e também ao poder aquisitivo deste proprietário;

- nível de conveniência de uso, aplicação;

- interesse de saúde pública;

- permanência de resíduos de medicamentos nos derivados da pecuária (carne, leite, ovos). Este é um dos principais limitantes para a comercialização e viabilização de produtos empregados na criação de animais de produção, o resíduo (concentração de princípios ativos encontrados nos tecidos destinados ao consumo humano) deve sempre ser o menor possível.

São muitos os desafios enfrentados em termos de sanidade animal atualmente. Considerando o mercado de bovinocultura de corte, têm-se desafios crescentes para combate de ecto e endoparasitas, na bovinocultura leiteira o controle das mastites, por exemplo, que quando não controladas acarretam em perdas de produção e má qualidade do leite. No setor de produção animal, os produtos devem apresentar como premissa boa eficácia com período mínimo de carência para os tecidos destinados ao consumo humano. No setor pet, exigem-se novas formas de administrações que facilitem o tratamento dos animais. Assim, com os crescentes desafios no setor, as empresas têm atribuído maior importância à área de pesquisa e desenvolvimento, fundamental para manutenção da competitividade comercial e estratégia da empresa (KOTLER, 2000 apud OMOTE; SLUSZZ, 2013).

Além dos desafios do próprio setor, dentro de uma empresa há alguns fatores que devem ser considerados e podem influenciar negativamente o processo de inovação tais como custos elevados, deficiência de demanda, fatores intrínsecos à empresa em razão de carência de capital humano especializado ou de conhecimentos específicos e fatores legais como regulações e regras tributárias (OECD, 2005).

Além dos desafios citados, a atividade de pesquisa e desenvolvimento também representa uma expressiva barreira de entrada no setor, devendo ser vista 
em conjunto com a existência de patentes que protegem o resultado da pesquisa e a diferenciação através da marca, obtida por meio de intensa atividade mercadológica (PALMEIRA-FILHO; PAN, 2003).

Mestre-Ferrandiz, Mordoh e Sussex (2012) comentam sobre quatro características desafiadoras no processo de pesquisa e desenvolvimento de novos produtos no contexto da indústria farmacêutica, podendo essas características serem extrapoladas para o setor veterinário. A primeira delas é que existe um alto grau de incertezas nas fases iniciais de pesquisas em decorrência de altos desafios científicos e falhas nas pesquisas clínicas. Em segundo lugar, os prazos para desenvolvimento de novos produtos são longos, podendo levar em média entre seis e sete anos para conclusão das pesquisas, além de mais dois anos para o processo de regulamentação. Em terceiro lugar, o custo de trazer novos medicamentos ao mercado é significativamente maior em comparação com outros setores. Estimativas na Europa citam custos para desenvolver um novo produto farmacêutico entre US\$ 150 milhões e US\$ 200 milhões, enquanto que em outros setores altamente inovadores, tais como os de tecnologias de informação e comunicações, o custo de trazer novos produtos para o mercado está em torno de US\$ 6.5 milhões (PAUL et al., 2010; COOKSEY, 2006; DIMASI; HANSEN; GRABOWSKI, 2003). E por fim, a quarta característica chave para o processo de P\&D, segundo Mestre-Ferrandiz, Mordoh e Sussex (2012), se dá com vínculo maior entre o setor privado e às universidades e instituições de pesquisa apoiadas pelo Estado.

A capacidade de geração de conhecimento de uma empresa, não necessariamente, reflete sua capacidade inovativa, o que justifica a busca do conhecimento externo. As principais fontes externas de conhecimento são os clientes, fornecedores, concorrentes e instituições públicas de pesquisa (ENKEL; GASSMANN, 2008 apud ENKEL; GASSMANN, CHESBROUGH, 2009). No Brasil, as fontes mais frequentes de conhecimento externo para o setor farmacêutico foram fornecedores, seguidos de clientes ou consumidores. Das farmacêuticas que tiveram alguma cooperação com outras organizações, cerca de $40 \%$ tiveram interação com Universidades e institutos de pesquisa (IBGE, 2011). 


\section{Oportunidades de inovação dentro das universidades}

As pesquisas realizadas dentro de universidades podem gerar resultados importantes para o desenvolvimento de um país (MAZZOLENI; NELSON, 2007). Elas atuam como formadoras de cientistas (capital humano) bem como produtoras de pesquisas e conhecimentos tecnológicos.

Segundo dados do Diretório de Grupos do Conselho Nacional de Desenvolvimento Científico e Tecnológico (CNPq, 2016) o número de grupos de pesquisa no Brasil, no ano de 2014, foi 35.424 . Isso representa um crescimento de cerca de $80 \%$ num período de 10 anos (em 2004, o total de grupos era de 19.470). As áreas que concentram o maior volume de grupos são Ciências Humanas, Ciências da Saúde e Ciências Aplicadas (juntas concentram 50\% do total). As áreas de Ciências Agrárias e Ciências Biológicas são representadas, respectivamente, por $9 \%$ e $10 \%$ dos grupos. A região Sudeste do país acumula $44 \%$ dos grupos de pesquisa. Estes dados ilustram brevemente a capacidade de instituições de pesquisa em fornecer conhecimento tecnológico e capital humano para o desenvolvimento da indústria nacional.

Considerando as áreas de pesquisa com temas relevantes para a inovação na indústria farmacêutica veterinária, a tabela 5 demonstra a distribuição de grupos de pesquisa no Diretório de Grupos do Conselho Nacional de Desenvolvimento Científico e Tecnológico (CNPq, 2016).

Reconhecendo a relevância da pesquisa acadêmica como fonte de conhecimentos para o avanço tecnológico, governos de vários países têm buscado incentivar a interação entre universidade e indústria bem como estimular a transferência de conhecimentos tecnológicos da universidade para o setor produtivo (MOWERY; SAMPAT, 2005). A detenção dos direitos de propriedade intelectual é muito importante para a transferência de tecnologia e licenciamento nos processos de inovação feitos em parceria entre empresas ou parcerias público-privadas, pois confere proteção e exclusividade de exploração de dada tecnologia. 
Tabela 5 - Classificação de grupos de pesquisa levantados na base de dados do CNPq, por tema e área predominante.

\begin{tabular}{|c|c|c|c|c|c|}
\hline \multirow[b]{2}{*}{ Tema } & \multicolumn{4}{|c|}{ Área Predominante } & \multirow[b]{2}{*}{ Total } \\
\hline & $\begin{array}{l}\text { Ciências } \\
\text { Agrárias }\end{array}$ & $\begin{array}{l}\text { Ciências } \\
\text { da Saúde }\end{array}$ & $\begin{array}{c}\text { Ciências } \\
\text { Biológicas }\end{array}$ & Outras & \\
\hline Anestesiologia & 44 & 10 & 0 & 0 & 54 \\
\hline Antialérgicos & 0 & 0 & 1 & 0 & 1 \\
\hline Antimicrobianos & 37 & 86 & 102 & 24 & 249 \\
\hline Antiparasitários & 6 & 11 & 6 & 13 & 36 \\
\hline $\begin{array}{l}\text { Doenças } \\
\text { Infecciosas }\end{array}$ & 94 & 224 & 87 & 9 & 414 \\
\hline Fitoterápicos & 28 & 112 & 58 & 26 & 224 \\
\hline $\begin{array}{l}\text { Liberação } \\
\text { controlada }\end{array}$ & 8 & 22 & 9 & 75 & 114 \\
\hline Nanotecnologia & 32 & 66 & 47 & 225 & 370 \\
\hline Nutrição animal & 163 & 3 & 11 & 5 & 182 \\
\hline $\begin{array}{l}\text { Reprodução } \\
\text { animal }\end{array}$ & 125 & 1 & 8 & 0 & 134 \\
\hline Vacinas & 35 & 62 & 136 & 7 & 240 \\
\hline Total & 572 & 597 & 465 & 384 & 2.018 \\
\hline
\end{tabular}

Fonte: CONSELHO NACIONAL DE DESENVOLVIMENTO CIENTÍFICO E TECNOLÓGICO. Diretório dos grupos de pesquisa no Brasil. Disponível em: http://lattes.cnpq.br/web/dgp/painel-dgp. Acesso em: 19/02/16.

O início do processo de patenteamento por parte das universidades se deu por volta da década de 80 , conforme relatado pelos trabalhos de Pinheiro-Machado e Oliveira (2004) e Póvoa (2008).

Póvoa (2008) verificou, por meio de levantamento de dados do Instituto Nacional da Propriedade Industrial (INPI), que as universidades paulistas, UNICAMP e USP apresentaram os maiores números de patentes depositadas no período compreendido entre 1979 e 2004 e, além disso, efetuaram depósitos em quase todos os subdomínios tecnológicos (27 de 30 ). Os autores revelaram ainda que as universidades brasileiras foram responsáveis por 34,5\% dos depósitos de "biotecnologia" e 28,6\% de "química orgânica" de residentes no Brasil, demonstrando uma significativa contribuição para setores "baseados na ciência". Outros autores também fizeram levantamentos anteriores e posteriores a este e o que se verifica é o aumento no número de depósitos de patentes no meio acadêmico ao longo do tempo bem como maior concentração de depósitos pelas universidades da região Sudeste (GARNICA, 2007; AMADEI; TORKOMIAN, 2009; GARNIKA, TORKOMIAN, 2009; OLIVEIRA; VELHO, 2009; PAVANELLI; OLIVEIRA, 2012). 
Com o intuito de ilustrar os depósitos de patentes pelas três universidades públicas do Estado de São Paulo, a tabela 6 apresenta as patentes disponíveis para licenciamento apresentadas nos portfólios de patentes relacionadas a áreas de grande interesse por parte das indústrias farmacêuticas veterinárias.

Tabela 6 - Patentes depositadas por tema dos grupos de pesquisa nas três universidades estaduais paulistas.

\begin{tabular}{|c|c|c|c|c|}
\hline & \\
\hline & Área & USP & UNESP & UNICAMP \\
\hline & $\begin{array}{c}\text { Saúde } \\
\text { Animal/Agropecuária }\end{array}$ & 8 & 2 & 37 \\
\hline & Saúde & 18 & 18 & 98 \\
\hline & Biotecnologia & 4 & 0 & 19 \\
\hline & Nanotecnologia & 10 & 0 & 90 \\
\hline & Química/Bioquímica & 0 & 9 & 19 \\
\hline & Total & 32 & 29 & 263 \\
\hline $\begin{array}{l}\text { Fontes: AGÊNCIA } \\
\text { <http://www.inova.unice } \\
\text { AGENCIA UNESP } \\
\text { em:<http://unesp.br/nit// } \\
\text { INOVAÇÃO. Históricc } \\
\text { em: } 12 \text { mar. } 2016 .\end{array}$ & $\begin{array}{l}\text { INOVA UNICAMP. } \\
\text { amp.br/empresas/tecnol } \\
\text { DE INOVAÇÃO. } \\
\text { /index_cat3_areas.php>. } \\
\text { o. Disponível em:<http }\end{array}$ & $\begin{array}{r}\text { Port } \\
\text { ogias-pa } \\
\text { Portfóli } \\
\text { Acessc } \\
: / / \text { inovac }\end{array}$ & $\begin{array}{l}\text { fólio de } \\
\text { tentes/>. } \\
\text { o de } \\
0 \text { em: } 25 \\
\text { ao.usp.br/s }\end{array}$ & $\begin{array}{l}\text { patentes. Disponível em: } \\
\text { Acesso em: 20 jan. 2016a; } \\
\text { tecnologia/patentes. Disponível } \\
\text { mar. 2016; AGÊNCIA USP DE } \\
\text { sobre-a-agencia/historico/>. Acesso }\end{array}$ \\
\hline
\end{tabular}

A tabela 6 descreve algumas patentes encontradas em temas de possível interesse para a indústria farmacêutica veterinária e ilustra a grande contribuição que o meio acadêmico pode oferecer.

No modelo de inovação aberta, no qual se busca o conhecimento externo, a universidade assume importante função no processo inovativo e, no contexto brasileiro, a participação desta instituição é essencial para o desenvolvimento econômico e social (CAMARGO; OLIVEIRA, 2016). A importância das patentes para as universidades se dá no apoio à inovação, uma vez que tecnologias universitárias protegidas podem ser licenciadas e permitem a criação de empreendimentos bem sucedidos, evitam a apropriação não autorizada do conhecimento e funcionam como uma receita adicional para as atividades de pesquisa (Agência Inova Unicamp, 2016b).

Assim, ao verificar o crescente número de depósitos universitários é possível inferir sobre maior preocupação e participação destes atores no cenário de inovação no Brasil. Por meio dos Núcleos de Inovação Tecnológica (NITs) é possível ter 
acesso ao portfólio de patentes das universidades e verificar possíveis oportunidades de parcerias entre estas e as empresas.

\section{Políticas de incentivo à inovação}

Existem atualmente políticas de incentivo à inovação e fontes financiadoras dos processos inovadores, sejam elas públicas ou privadas. Em relatório emitido pelo IBGE (2013), no ano de 2011 , os principais instrumentos utilizados pelas empresas inovadoras foram o financiamento para compra de máquinas e equipamentos $(25,6 \%)$ e outros programas de apoio, que agregam as bolsas oferecidas pelas Fundações de Amparo à Pesquisa - FAPs e pelo Programa Recursos Humanos para Áreas Estratégicas - RHAE-Inovação, do Conselho Nacional de Desenvolvimento Científico e Tecnológico - CNPq, os programas de aporte de capital de risco do Banco Nacional de Desenvolvimento Econômico e Social - BNDES e da Financiadora de Estudos e Projetos - Finep, e outros, como compra governamental, incentivos fiscais concedidos pelos estados especificamente para o desenvolvimento de P\&D (7,9\%). Os menos utilizados foram a subvenção econômica $(1,0 \%)$ e o financiamento a projetos de P\&D e inovação tecnológica em parceria com universidades ou institutos de pesquisa $(1,3 \%)$.

O apoio governamental à inovação pode ocorrer de duas formas: apoio indireto (Incentivos Fiscais) e apoio direto (Captação de Recursos). Os incentivos fiscais se configuram de duas formas: dedução do imposto de renda e crédito fiscal. No Brasil, os incentivos fiscais à inovação estão concentrados principalmente na Lei № 11.196 (Lei do Bem), que consolidou os incentivos que as firmas podem usufruir de forma automática caso realizem pesquisa tecnológica e desenvolvimento de inovação tecnológica. Os incentivos de apoio direto se dão por meio de instrumentos de financiamento aos projetos de inovação disponibilizados através das agências e bancos de fomento, como a FINEP, o BNDES, as fundações estaduais de pesquisa, dentre outras. Uma forma de incentivo direto é a subvenção econômica, que consiste na aplicação de recursos públicos não reembolsáveis (que não precisam ser devolvidos) nas empresas, compartilhando com elas os custos e riscos do projeto (PEREIRA; RIGHI; LOURES, 2013).

Em 2013 o Brasil teve um dispêndio total de cerca de $R \$$ 63,8 milhões em $P \& D$. Deste total, $R \$ 36,8$ milhões foram dispêndios do governo estadual e federal 
sob a forma de bolsas do CNPq, Capes, fundações de amparo à pesquisa, dispêndios dos institutos de pesquisa e gastos com a pós-graduação em programas reconhecidos pela Capes. Os outros $R \$ 26,9$ milhões foram dispendidos pelo setor empresarial (privado e público) nas atividades internas e externas de P\&D, bem como, gastos com pós-graduação em programas reconhecidos pela Capes.

De acordo com a FAPESP (2016), os Estados também contribuem com uma fração da receita líquida real para dispêndios em pesquisa desenvolvimento, com maior investimento nos estados de São Paulo, Paraná, Rio de Janeiro e Bahia.

Os dispêndios informados na figura 1 são expressos em valores percentuais, dados como fração da receita líquida real dos Estados (receita anual, excluindo receitas provenientes de operações de crédito, alienação de bens, transferências voluntárias, doações recebidas com o fim específico de atender despesas de capital e as transferências aos municípios). Os dados levam em consideração o orçamento executado, definido como dispêndios em P\&D com origem nos orçamentos de órgãos estaduais (exceto instituições de ensino superior), incluindo institutos de pesquisa e agências/fundações de apoio à pesquisa; bem como orçamentos de ensino superior que são os dispêndios em P\&D com origem nos orçamentos das instituições de ensino superior (universidade e outras) estaduais. Foram incluídos os estados com pelo menos $0,5 \%$ de esforço em P\&D e aqueles com frações menores foram agregados em "demais estados". 
Figura 1 - Dispêndio em pesquisa e desenvolvimento (P\&D) como fração da receita líquida real dos Estados, orçamento executado e ensino superior.

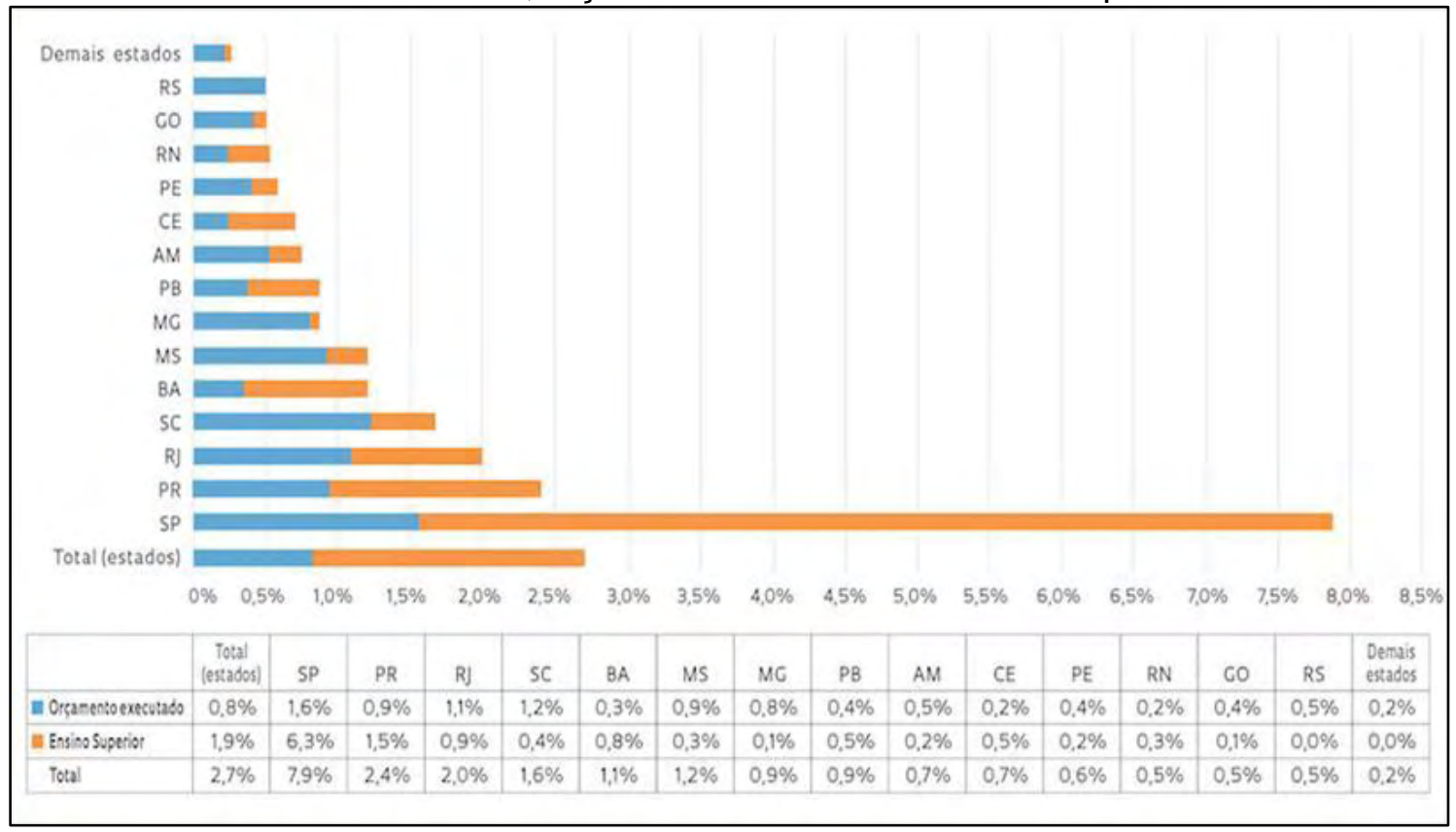

Fonte: FUNDAÇÃO DE AMPARO À PESQUISA DO ESTADO DE SÃO PAULO - FAPESP. EsforçO estadual em P\&D. Revista Pesquisa FAPESP, São Paulo, n. 240, Fev. 2016. Disponível em: <http://revistapesquisa.fapesp.br/2016/02/19/folheie-a-edicao-240/>. Acesso em: 24 abr. 2016.

Segundo a pesquisa PINTEC realizada pelo INSTITUTO BRASILEIRO DE GEOGRAFIA E ESTATÍSTICA (IBGE) em 2011, 77\% das empresas farmacêuticas no Brasil utilizaram recursos próprios para desenvolver atividades de P\&D interno, e 84\% utilizaram recursos próprios para desenvolver outras atividades inovativas, como a aquisição externa de P\&D, por exemplo. A participação do governo no financiamento de atividades internas de $P \& D$, segundo essa pesquisa, foi de $17 \%$.

\section{Considerações finais}

Os grandes líderes de mercado na indústria farmacêutica veterinária nacional são as empresas multinacionais, embora três empresas nacionais apareçam no ranking das oito maiores de 2012. A maior demanda por produtos veterinários ocorre para as espécies produtoras de alimento e, as classes de produtos com maior participação no mercado são antiparasitários e biológicos.

Pelo levantamento de patentes dessas companhias verifica-se também maior potencial inovativo das empresas internacionais, haja vista a grande quantidade de patentes depositadas. Considerando que o faturamento de tais empresas é cerca de 
dez vezes o faturamento de uma empresa nacional, este cenário seria mesmo o esperado.

A variedade de espécies domésticas desafia a indústria veterinária pelas distintas necessidades de cada uma, pelo valor de cada espécie e pelo grau de relacionamento dos proprietários com cada uma delas. Ao mesmo tempo, essa distinção de espécies e sua aptidão (produção de alimentos, animais de companhia) trazem possibilidades de inovação para que as diferentes necessidades de mercado sejam atendidas.

O levantamento das patentes depositadas no Brasil pelas principais empresas farmacêuticas veterinárias destacou maior número de depósitos na área de produtos antiparasitários e biológicos.

Foi verificado também número considerável de patentes disponíveis para licenciamento nas universidades públicas paulistas (USP, UNESP e UNICAMP) em área de possível interesse para a indústria. A existência de patentes universitárias mostra que existe preocupação do meio acadêmico na proteção do conhecimento e das tecnologias produzidas, e ainda abre possibilidades de parcerias públicoprivadas para que aquilo que foi produzido possa ser transformado em um produto, gerando valor para a sociedade.

Um ponto interessante sobre as patentes, no contexto deste trabalho, é que elas podem ser interpretadas como demanda e oportunidade. Indicadores de oportunidade, pois as empresas podem ter acesso aos portfólios de patentes disponibilizados pelos Núcleos de Inovação Tecnológica (NITs) e traçar parcerias externa para pesquisa e desenvolvimento de novos produtos. Indicadores de demanda, pois os depósitos da iniciativa privada podem representar um termômetro de tendências do mercado, intenções de novos produtos que talvez as pesquisas realizadas dentro das Universidades possam suprir.

No levantamento de dados deste trabalho foi observada ainda enorme quantidade de grupos de pesquisa nos diversos temas de interesse para a indústria veterinária, o que também possibilita oportunidades de parcerias entre os dois atores para a promoção de novas soluções tecnológicas.

Verificou-se que o Estado fomenta a inovação de duas formas principais: apoio indireto (Incentivos Fiscais) e apoio direto (Captação de Recursos). E a maioria das empresas que geram inovações usam recursos próprios para as atividades de P\&D. 
A alta competitividade do mercado, emergência de novas doenças nos animais, possibilidades de mudanças nas regulamentações, aumento da criticidade das pessoas quanto à segurança de alimentos, bem estar animal são apenas alguns aspectos que ilustram a necessidade de inovação e de agilidade no processo de inovação neste setor. Nesse contexto a parceria entre empresas e universidades pode ser algo positivo e estudos futuros são importantes para verificar como ocorrem essas parcerias na área veterinária.

\section{Referências}

AGÊNCIA INOVA UNICAMP. Portfólio de patentes. Disponível em: $<$ http://www.inova.unicamp.br/empresas/tecnologias-patentes/>. Acesso em: 20 jan. 2016a.

AGÊNCIA INOVA UNICAMP. Importância da propriedade intelectual nas atividades de pesquisa e inovação. Disponível em:

$<\mathrm{http}: / /$ www.inova.unicamp.br/sites/default/files/documents/Importancia_da_Propried ade $<$ Intelectual_nas_atividades_de_pesquisa_e_inovacao-artigo.pdf $>$. Acesso em: 12 mar. 2016b.

AGÊNCIA UNESP DE INOVAÇÃO. Portfólio de tecnologia/patentes. Disponível em:<http://unesp.br/nit/index_cat3_areas.php>. Acesso em: 25 mar. 2016.

AGÊNCIA USP DE INOVAÇÃO. Histórico. Disponível em:<http://inovacao.usp.br/sobre-a-agencia/historico/>. Acesso em: 12 mar. 2016.

AHAMED, I.; KASRAIAN, K. Pharmaceutical challenges in veterinary product development. Advanced Drug Delivery Reviews, Amsterdam, v. 54, n. 6, p. 871882, 2002.

ALEXANDER, A. et al. Approaches for breaking the barriers of drug permeation through transdermal drug delivery. Journal of Controlled Release, Amsterdam, v. 164, n. 1, p. 26-40, 2012.

AMADEI, J. R. P.; TORKOMIAN, A. L. V. As patentes nas universidades: análise dos depósitos das universidades públicas paulistas. Ciência da Informação, Brasília, v. 38, n. 2, p. 9-18, maio/ago. 2009.

ANIMAL PHARM. Animal health industry rankings 2014: are the leaders better together or stronger apart? 2015. Disponível em: <https://www.agranet.com/agra/animal-pharm/analysis/animal-health-industry-rankings-2014-are-theleaders-better-together-or-stronger-apart-478068.htm>. Acesso em: 14 dez. 2016.

ANIMAL PHARM. Patent archive. Disponível em:<https://www.agranet.com/agra/animal-pharm/data/patent-archive/>. Acesso em: 14 dez. 2016. 
ARYA, J. M. et al. Rabies vaccination in dogs using a dissolving micro needle patch. Journal of Controlled Release, Amsterdam, v. 239, p. 19-26, 2016.

ASSOCIAÇÃO BRASILEIRA DA INDÚSTRIA E DE PRODUTOS PARA ANIMAIS DE COMPANHIA - ABINPET. População de pets cresce $5 \%$ ao ano e Brasil é quarto no ranking mundial. 2013. Disponível em:<http://abinpet.org.br/site/portal-mfpopulacao-de-pets-cresce-5-ao-ano-e-brasil-e-quarto-no-ranking-mundial/>. Acesso em: 10 jun. 2014.

BANCO NACIONAL DE DESENVOLVIMENTO ECONÔMICO E SOCIAL - BNDES. Informe Setorial: área industrial, Brasília, n. 27, p.1-6, nov. 2013.

BRASIL. Lei no 10.973, de 02 de dezembro de 2004. Dispõe sobre incentivos à inovação e à pesquisa científica tecnológica no ambiente produtivo e dá outras providências. Diário Oficial [da] União, Brasília, DF, 3 dez. 2004.

CAMARGO, C.; OLIVEIRA, M. F. Universidade brasileira e inovação: uma revisão sistemática da literatura. In: CONGRESSO IBERO-AMERICANO DE INVESTIGAÇÃO QUALITATIVA, 5., 2016, Porto. Proceedings... Porto, 2016. v. 3, p. 228-237. Disponível em:

<http://proceedings.ciaiq.org/index.php/ciaiq2016/article/view/946/929>. Acesso em: 16/12/16.

CAPANEMA, L. X. L. et al. Panorama da indústria farmacêutica veterinária. BNDES Setorial, Rio de Janeiro, n. 25, p. 157-174, 2007.

COMISSÃO EUROPÉIA. Comunicação da Comissão ao Parlamento Europeu e ao Conselho. Plano de acção contra a ameaça crescente da resistência antimicrobiana. Bruxelas, 2011.17 p.

CONSELHO NACIONAL DE DESENVOLVIMENTO CIENTÍFICO E TECNOLÓGICO - CNPq. Diretório dos grupos de pesquisa no Brasil. Disponível em: <http://lattes.cnpq.br/web/dgp/painel-dgp>. Acesso em: 19 fev. 2016.

COOKSEY, D. A review of UK health research funding. London: HM Treasury, 2006. $121 \mathrm{p}$.

CRUZ, B. C. Ocorrência de resistência de Rhipicephalus (Boophilus) microplus (Acari:Ixodidae) à ivermectina administrada em bovinos de São Paulo e Minas Gerais, Brasil. 2013. 120 f. Dissertação (Mestrado Medicina Veterinária) Faculdade de Ciências Agrárias e Veterinárias, Jaboticabal, 2013.

DIMASI, J.; HANSEN, R. W.; GRABOWSKI, H. G. The price of innovation: new estimates of drug development costs. Journal of Health Economics, Amsterdam, v. 22, p. 151-185, 2003.

ENKEL, E.; GASSMANN, O.; CHESBROUGH, H. Open R\&D and open innovation: exploring the phenomenon. R\&D Management, v. 39, n. 4, p. 311-316, set., 2009. 
FUNDAÇÃO DE AMPARO À PESQUISA DO ESTADO DE SÃO PAULO - FAPESP. Esforço estadual em P\&D. Revista Pesquisa FAPESP, São Paulo, n. 240, Fev. 2016. Disponível em: <http://revistapesquisa.fapesp.br/2016/02/19/folheie-a-edicao240/>. Acesso em: 24 abr. 2016.

GARNICA, L. A. Transferência de tecnologia e gestão da propriedade intelectual em universidades públicas no estado de São Paulo. 2007. 206 f. Dissertação (Mestrado em Engenharia de Produção) - Centro de Ciências Exatas e de Tecnologia, Universidade Federal de São Carlos, São Carlos, 2007.

GARNICA, L. A.; TORKOMIAN, A. L. V. Gestão de tecnologia em universidades: uma análise do patenteamento e dos fatores de dificuldade e de apoio à transferência de tecnologia no Estado de São Paulo. Gestão da Produção, São Carlos, v. 16, n. 4, p. 624-638, out./dez. 2009.

HOLSBACK, L. et al. Resistência de Haemonchus, Cooperia, Trichostrongylus e Oesophagostommum à ivermectina em bovinos de leito no Paraná. Semina:

Ciências Agrárias, Londrina, v. 36, n. 3, supl. 1, p. 2031-2036, 2015.

INSTITUTO BRASILEIRO DE GEOGRAFIA E ESTATÍSTICA - IBGE. Pesquisa de inovação. Rio de Janeiro: IBGE, 2013. Disponível em:<http://www.pi ntec.ibge.gov.br/downloads/pintec2011\%20publicacao\%20completa pdf $>$. Acesso em: 29 set. 2014.

INSTITUTO NACIONAL DA PROPRIEDADE INDUSTRIAL - INPI. Base de patentes. Disponível

em:<https://gru.inpi.gov.br/pePl/jsp/patentes/PatenteSearchBasico.jsp>. Acesso em: 15 dez. 2016.

KAMIMURA, Q. P.; CORNETTA, V. K. Inovação e propriedade intelectual no setor farmacêutico: desafios governamentais e efeitos na saúde pública. In: ENCONTRO NACIONAL DE ENGENHARIA DE PRODUÇÃO, 31., 2011, Belo Horizonte. Anais eletrônicos... Belo Horizonte, 2011. Disponível em:

<http://www.abepro.org.br/biblioteca/enegep2011_TN_STO_135_855_18348.pdf>. Acesso em: 10 dez. 2016.

KOHL, T.; PONTAROLO, G. H.; PEDRASSANI, D. Resistência antimicrobiana de bactérias isoladas de amostras de animais atendidos em hospital veterinário. Saúde e Meio Ambiente, Mafra, SC, v. 5, n. 2, p. 115-127, 2016.

LIMA, L. I. Desenvolvimento de uma nanoformulação autoemulsificante contendo alcaloide epiisopiloturina para melhorar sua biodisponibilidade plasmática após administração via oral. 2016. 61 f. Dissertação (Mestrado Nanociência e Nanobiotecnologia) - Instituto de Ciências Biológicas, Universidade de Brasília, Brasília, 2016.

MATIAS, J. et al. Relação entre a comercialização e a eficiência de acaricidas no Estado de Mato Grosso do Sul. Campo Grande, MS: Embrapa Gado de Corte, 2011. 30 p. 
MAZZOLENI, R.; NELSON, R. R. Public research institutions and economic catchup. Research Policy, Amsterdam, v. 36, n. 10, p. 1512-1528, dez. 2007.

MCKAY, P. F. et al. Intravaginal immunization using a novel antigen-releasing ring device elicits robust vaccine antigen-specific systemic and mucosal humoral immune responses. Journal of Controlled Release, Amsterdam, v. 249, p. 74-83, 2017.

MENDES, M. C. et al. Resistance to cypermethrin, deltamethrin and chorpyriphos in populations of Rhipicephalus (Boophilus) microplus (Acari:Ixodidae) from small farms of the State of São Paulo, Brazil. Veterinary Parasitology, Amsterdam, v. 178, p. 383-388, 2011.

MESTRE-FERRANDIZ, J.; MORDOH, A.; SUSSEX, J. The many faces of innovation. London: Association of the British Pharmaceutical Industry, 2012. 65 p.

MOWERY, D.; SAMPAT, B. Universities in national innovation systems. In: FARGERBERG, J; MOWERY, D.; NELSON, R. The Oxford handbook of innovation. Oxford: Oxford University, 2005. p. 209-239.

NEVES, J. H. Diagnóstico de resistência anti-helmíntica em bovinos. 2014. $72 \mathrm{f}$. Dissertação (Mestrado Medicina Veterinária) - Faculdade de Medicina Veterinária e Zootecnia, Jaboticabal, 2014.

OLIVEIRA, R. M.; VELHO, L. M. L. S. Patentes acadêmicas no Brasil: uma análise sobre as universidades públicas paulistas e seus inventores. Parcerias Estratégicas, Brasília, v. 14, n. 29, p. 173-200, jul./dez. 2009.

OMOTE, H. S. G.; SLUSZZ, T. Prospecção de Mercado visando P\&D para medicamentos veterinários para bovinocultura no Brasil. Revista GEINTEC, Aracajú, v. 3, n. 5, p. 129-147, 2013.

ORGANIZAÇÃO PARA COOPERAÇÃO ECONÔMICA E DESENVOLVIMENTO OECD. Manual de Oslo: diretrizes para coleta e interpretação de dados sobre inovação. 3. ed. Rio de Janeiro: FINEP, 2005.

ORTIZ, P. Zoetis: uma empresa comprometida em apresentar inovações para a saúde animal: depoimento. [06 de novembro de 2014]. Entrevista concedida à Associação Nacional de Criadores e Pesquisadores.

PALMEIRA FILHO, P. L.; PAN, S. S. K. Cadeia farmacêutica no Brasil: avaliação preliminar e perspectivas. BNDES Setorial, Rio de Janeiro, n. 18, p. 3-22, set. 2003.

PAUL, S. M. et al. How to improve R\&D productivity: the pharmaceutical industry's grand challenge. Nature Reviews Drug Discovery, London, v. 9, p. 203-214, 2010.

PAVANELLI, M. A.; OLIVEIRA, E. F. T. Conhecimento tecnológico e inovação no Brasil: um estudo patentométrico na Universidade Estadual Paulista. Ibersid, Zaragoza, v. 2, p. 119-125, 2012. 
PEREIRA, J. S. et al. Improving the feline veterinary consultation: the usefulness of Feliway spray in reducing cats' stress. Journal of Feline Medicine and Surgery, London, v. 18, n. 12, p. 959-964, 2016.

PEREIRA, R.; RIGHI, H.; LOURES, M. et al. Pesquisa: fomento para inovação nas empresas brasileiras. Caderno de Ideias FDC, Nova Lima, p. 1-11, 2013. Disponível em:

<http://acervo.ci.fdc.org.br/AcervoDigital/Cadernos\%20de\%20ld\%C3\%A9ias/2013/Cl 1306.pdf>. Acesso em: 12 dez. 2016.

PINHEIRO-MACHADO, R.; OLIVEIRA, P. L. A comparative study of patenting activity in U.S. and Brazilian scientific institutions. Scientometrics, Budapest, v. 61, n. 3, p. 323-338, 2004.

PÓVOA, L. M. C. Patentes de universidades e institutos públicos de pesquisa e a transferência de tecnologia para empresas no Brasil. 2008. 153 f. Tese (Doutorado em Economia) - Centro de Desenvolvimento e Planejamento Regional, Faculdade de Ciências Econômicas da Universidade Federal de Minas Gerais, Belo Horizonte, 2008.

SANTORO, F. M. Innovación y sendero evolutivo en la industria farmacéutica: los casos de Argentina y España. São Paulo: CYTED:PGT/USP, 2000. 83 p. (Cadernos de gestão tecnológica, 48).

SILVA, N. T. R. Proposta de um modelo para geração e análise das oportunidades de mercado e tecnológica para o desenvolvimento de produtos farmacêuticos veterinários. 2009. 230 f. Dissertação (Mestrado Ciências Farmacêuticas) - Faculdade de Ciências Farmacêuticas de Ribeirão Preto, Ribeirão Preto, 2009.

SINDICATO NACIONAL DA INDÚSTRIA DE PRODUTOS PARA SAÚDE ANIMAL SINDAN. Mercado. Disponível em:

<http://www.sindan.org.br/sd/base.aspx?controle=8>. Acesso em: 12 jan. 2015.

SOUZA, M. A.; MURAKAWA, L. S. G. Guia prático I: introdução à propriedade intelectual. São Paulo: Agência USP de Inovação, 2014. Disponível em:

<http://www.inovacao.usp.br/cartilhas/PI_Cartilha.pdf>. Acesso em: 30 jan. 2017.

THAKUR, R. R. S.; McMILLAN, H. L.; JONES, D. S. Solvent induced phase inversion-based in situ forming controlled release drug delivery implants. Journal of Controlled Release, Amsterdam, v. 176, p. 8-23, 2014. 


\section{Capítulo 2}

Aguardando parecer do editor , artigo encaminhado para publicação na Revista Eletrônica de Administração 


\section{Análise da interação entre a indústria farmacêutica veterinária e os grupos de pesquisa no contexto de inovação}

\section{RESUMO}

A pesquisa teve como objetivo avaliar o estado da arte da inovação no setor de saúde animal, tanto no sentido de saber como e o que está sendo produzido, quanto à verificação de possíveis interações com as universidades. Ainda, a ausência de trabalhos publicados avaliando os tipos de patentes depositadas, bem como os grupos de pesquisa que atuam, direta ou indiretamente, nesta área fortaleceu a necessidade de iniciar uma pesquisa nesse sentido. Assim, por meio do levantamento e classificação de patentes depositadas, no Brasil, por indústrias de saúde animal e universidades públicas bem como estudo dos grupos de pesquisa do CNPq, buscou-se verificar o perfil de produção científico/tecnológica entre os dois atores principais (públicos e privados). Além disso, pontuou-se o que existe de demanda e oportunidade para inovação em saúde animal e fez-se uma primeira análise do nível de interação entre os grupos de pesquisa, que poderiam representar oportunidades de inovação, e empresas. Os resultados mostraram que o perfil de produção científica e tecnologia dos dois atores envolvidos, indústria e universidades, é distinto. Observa-se que as empresas de saúde animal apresentam maior número de depósitos de patente nas áreas de produtos biológicos e antiparasitários, enquanto as universidades apresentam pesquisas mais diluídas em temas de interesse para o setor de saúde animal, o que foi verificado tanto nas patentes depositadas quando na avaliação dos grupos de pesquisa. Ainda, verificouse que, dos grupos avaliados, poucos declararam alguma parceria com instituições privadas. De uma forma geral, está sendo produzido conhecimento muito valioso nas universidades brasileiras que pode ser trabalhado em prol de colocar novas alternativas de medicamentos e terapias veterinárias. Neste contexto, acredita-se que a maior cooperação entre universidade e empresas da área de saúde animal poderá beneficiar o mercado e a sociedade com novas soluções.

Palavras-chave: Inovação. Saúde-animal. Interação universidade-empresa. 


\begin{abstract}
The goal of this research was to evaluate the state of art on innovation of the animal health sector, studying what has been produced and how, and the possible interactions with universities. The absence of published papers evaluating patents as well as the research groups that act, directly or indirectly, in the area of animal health have strengthened the need to initiate this research. Thus, through the survey and classification of patents registered in Brazil by animal health companies and public universities, as well as the evaluation of CNPq research groups, we sought to verify the scientific / technological production profile between the two main parties (public and private). In addition, this work pointed out the existing demand and opportunity for innovation in animal health and an initial analysis of the level of interaction between research groups and companies was made. The results showed that the scientific -technological production profile of the two parties is distinct. It was observed that animal health companies showed greater registration of patents on the areas of biological and antiparasitic products, while universities had patent registration more distributed on the topics of interest for animal health. These observations were true for both, registered patents and research groups. Also, it was observed that the majority of the research groups do not state a partnership with a private company in the animal health industry. In general, information is created in Brazilian universities, and it can be used on the development for new alternatives for veterinary medicines and therapies. In conclusion, it is possible that greater cooperation between universities and animal health companies could benefit the market and the society with new solutions.
\end{abstract}

Keywords: Innovation. Animal health. University-industry partnership.

\title{
RESUMEN
}

La investigación ha objetivado evaluar el estado de arte de la innovación en el sector de salud animal, en el ámbito de saber lo que está siendo producido y como está siendo producido, así como la verificación de posibles interacciones con las universidades. Así mismo, la inexistencia de trabajos publicados evaluando los tipos de patentes inscritas, así como los grupos de investigación que actúan, directa o indirectamente, en esta área fortaleció la necesidad de empezar una investigación en este sentido. Por lo tanto, por medio del levantamiento y clasificación de patentes inscritas, en Brasil, por industrias de salud animal y universidades públicas bien 
como el estudio de los grupos de investigación de CNPq, se buscó verificar el perfil de producción científica/tecnológica entre los dos actores principales (públicos y privados). Además de esto, se destacó lo que existe de demanda y oportunidades para innovación en salud animal y se hizo un primer análisis del nivel de interacción entre los grupos de investigación que podrán representar oportunidades de innovación y empresas. Los resultados mostraron que el perfil de producción científica y tecnológica de los dos actores envueltos, industria y universidad, es distinto. Se observa que las empresas de salud animal presentan un mayor número de patentes inscritas en el área de productos biológicos y antiparasitarios, mientras que las universidades presentan investigaciones más diluidas en temas de interés para el sector de salud animal, lo que fue verificado tanto en las patentes inscritas, así como en la evaluación de los grupos de investigación. Así mismo, se verifico que, de los grupos evaluados, pocos declaran un convenio con instituciones privadas. En amplio rasgo, está siendo producido conocimiento muy valioso en las universidades brasileiras que puede ser trabajado en pro de colocar nuevas alternativas de medicamentos y terapias veterinarias. En este contexto, se cree que una mayor cooperación entre universidades y empresas del área de salud animal podrá beneficiar el mercado y la sociedad con nuevas soluciones.

Palabras clave: Innovación. Salud animal. Interacción universidad empresa.

\section{Introdução}

A indústria veterinária é corresponsável pela manutenção da sanidade e desempenho dos animais, uma vez que disponibiliza produtos e serviços ao agronegócio a fim de garantir a sanidade dos rebanhos bovinos, suínos e aves que serão destinados à produção de alimentos. Elevando-se o status sanitário dos animais e se empregando medidas profiláticas e programas de melhoria do desempenho, eleva-se a competitividade do negócio de proteínas no Brasil (SALANI, 2015). Além disso, a indústria veterinária é crucial para promover a saúde e bem estar de animais domésticos (CAPANEMA et al., 2007), hoje tratados muitas vezes como membros da família.

A indústria farmacêutica, tanto humana quanto veterinária, compartilha princípios ativos, modelos de produção e pesquisa. Essa similaridade operacional facilita os negócios por propiciar a divisão dos elevados custos de Pesquisa e 
Desenvolvimento (P\&D), o incremento das atividades, além de alavancar os lucros com as vendas dos produtos veterinários, objetivando o retorno do investimento nessa área e na área humana (AHMED; KASRAIAN, 2002; CAPANEMA et al., 2007).

Dois modelos de indústria veterinária predominam no mercado atual: empresas internacionais de grande porte, líderes em inovação com atuação global, e empresas nacionais de menos porte, especializadas em necessidades locais e nichos de mercado (CAPANEMA et al., 2007).

O domínio do mercado de saúde animal é exercido por empresas multinacionais. Dentre as dez maiores, quatro atuam exclusivamente na área veterinária, enquanto que as outras seis são divisões veterinárias de conglomerados farmacêuticos focados em saúde humana (BNDES, 2013).

Dados publicados no site do Sindicato Nacional da Indústria de Produtos para Saúde Animal (SINDAN, 2015) mostram, no Brasil, um faturamento crescente no setor de saúde animal nos últimos seis anos. A ascensão das empresas brasileiras baseou-se principalmente na expansão do mercado de biológicos, aproveitando a oportunidade gerada pelas campanhas de vacinação contra a febre aftosa.

A indústria farmacêutica é uma das mais rentáveis e se caracteriza por agressividade mercadológica, alta capacidade de inovação e por estratégias defensivas para proteger o seu mercado de novos entrantes (outras empresas ou novos produtos) (CAPANEMA; PALMEIRA-FILHO, 2007). Este ambiente competitivo faz desta indústria uma das mais inovadoras, sendo as multinacionais as grandes propulsoras dos principais avanços tecnológicos na área da saúde. Estendendo este cenário para a indústria farmacêutica veterinária, somado ao promissor mercado existente, é possível destacar a importância de investimentos em inovação também neste setor.

O presente trabalho teve como objetivo analisar dados de patentes depositadas no Brasil como um indicador de inovação tecnológica no setor de saúde animal, visando verificar a demanda (patentes depositadas pelas indústrias farmacêuticas veterinárias) e oportunidades de inovação e parcerias (patentes depositadas pelas universidades, grupos de pesquisa do $\mathrm{CNPq}$ ), além de verificar se o perfil de produção científica e tecnológica das universidades e empresas no setor de saúde animal é similar, e refletir sobre o nível de relação entre os dois atores neste setor. 


\section{Referencial teórico}

2.1 Inovação na Indústria Farmacêutica

Segundo a (ORGANIZAÇÃO PARA COOPERAÇÃO ECONÔMICA E DESENVOLVIMENTO, 2005) a Inovação pode ser definida como:

“...uma implementação de um produto (bem ou serviço) novo ou significativamente melhorado, ou um processo, ou um novo método de marketing, ou um novo método organizacional nas práticas de negócios, na organização do local de trabalho ou nas relações externas".

A inovação na indústria farmacêutica pode ocorrer de forma incremental, quando apresenta pequenas modificações ou adaptações em um produto ou processo já existente. Bem como na forma de inovação radical ou de ruptura, que ocorre, por exemplo, quando há o desenvolvimento de uma nova molécula, a qual pode levar a um novo medicamento passível de ser patenteado (KAMIMURA; CORNETTA, 2011).

Yamaguishi (2014) argumenta que para a indústria farmacêutica brasileira, a estratégia de inovação está atrelada à proteção da propriedade intelectual, à capacidade de produção, bem como à estratégia comercial. Além disso, identificou como oportunidades de melhoria do processo de inovação no setor, o monitoramento de patentes que estão próximas à data de expiração, acompanhamento das atividades de pesquisa clínica de empresas concorrentes e a busca de oportunidade para o desenvolvimento de produtos similares àqueles inovadores. Ainda, indicou que a principal estratégia de inovação, dentro das indústrias farmacêuticas nacionais, é a inovação incremental justificada pelo fato de serem desenvolvidos produtos similares com intuito de reduzir os custos e riscos do processo.

A introdução da Lei de Patentes em 1996 e da Lei do Medicamento Genérico em 1999 acarretaram mudanças na estratégia do processo de inovação da indústria farmacêutica humana. As empresas farmacêuticas tinham estratégias voltadas para a fixação de marcas, controle dos canais de distribuição e grandes equipes de venda. Com a chegada das duas leis, tornou-se impossível a cópia de produtos referência com patentes vigentes e a fabricação dos genéricos passou a ter regulamentação mais vigorosa (SANTOS; PINHO, 2012). Com essas mudanças, 
Santos e Pinho (2012) identificaram maior intensificação do esforço tecnológico nas empresas nacionais, tendo como estratégias de inovação o maior investimento em prospecção tecnológica, bem como a formação de equipes internas voltadas para isso e maior importância dos institutos de pesquisa e universidades para geração da inovação.

Outro paradigma importante se refere ao nível crescente de globalização dos mercados nestas últimas décadas, que atua como um fator vital para aumentar a concorrência e a consequente competitividade dentro das empresas, além de estimular a criação de inovações tecnológicas no setor privado e acadêmico (AMADEI; TORKOMIAN, 2009; HAASE; ARAÚJO; DIAS, 2005). Com isso, a fim de se manter competitiva, uma empresa tem como possibilidades comprar tecnologia, desenvolver sua capacidade de P\&D ou estabelecer parcerias com universidades e centros de pesquisa (BONACCORSI;PICCALUGA, 1994; STAL, 1999; SCHREINER, 2007 apud GONÇALO; ZANLUCHI, 2011).

$\mathrm{Na}$ extensão de nosso conhecimento, não há estudos publicados sobre estratégias de inovação no setor de saúde animal.

\subsection{Interação Universidade-Empresa}

Em países considerados desenvolvidos, como os Estados Unidos, por exemplo, as universidades tem grande importância na trajetória de inovação. Este país adotou a estratégia de apoio à pesquisa básica nas universidades norte-americanas (fornecimento de fundos e estreitamento da relação universidade e indústria), após a Segunda Guerra Mundial, como forma de recuperar sua economia. Neste país, as universidades são consideradas elementos estratégicos para o desenvolvimento econômico e tecnológico (MOWERY; ROSENBERG, 2005 apud AMADEl; TORKOMIAN, 2009).

No Brasil, diversos autores enfatizam a importância da cooperação entre empresas e universidades para a produção de conhecimento e a sua transformação em novas tecnologias produtivas (BATISTA et al., 2013; BERNI et al., 2015; NASCIMENTO, 2011). Tal interação contribui para a maior competitividade da empresa (ANDREASSI, 2007 apud BATISTA et al., 2013). Rattner (1984) e Cruz e Pedrozo (2008) ainda acrescentam que essa interação pode ser muito importante 
para pequenas e médias empresas, as quais, no geral, encontram maiores dificuldades para financiar atividades de Pesquisa e Desenvolvimento (P\&D) internas. Para Gonçalo e Zanluchi (2011) o desenvolvimento de P\&D doméstico pode ser inviável frente ao tempo necessário para se aproximar dos atuais níveis de P\&D das grandes empresas internacionais. Assim, é possível inferir que o estabelecimento de parcerias com universidades é uma opção estratégica que promoveria o desenvolvimento de competências necessárias às próprias empresas.

Contudo, algumas questões oriundas da essência da nossa cultura, ainda dificultam um pouco o trabalho conjunto destes dois importantes atores deste segmento. Gonçalo e Zanluchi (2011) apontam, de um lado, para a burocracia da universidade brasileira, seguido, pelo outro lado, pela premissa "meu negócio não necessita de apoio externo" como fatores para o não desenvolvimento de projetos em parceria. Batista et al. (2013) descrevem como fatores não sinérgicos o fato das universidade desenvolverem pesquisas mais centradas em seu próprio interesse e o de seus pesquisadores do que nas necessidades das empresas e do mercado, e ainda que o interesse das empresas é, muitas vezes, tido como ilegítimo pelas universidades. Além disso, algumas empresas tem uma visão de curto prazo, diferente da visão de médio e longo prazo das universidades, em relação ao tempo para realização de um projeto de pesquisa, já que a motivação da indústria está atrelada a uma oportunidade de retorno identificada no mercado.

Apesar da complexidade, o trabalho em conjunto entre universidade e empresas sinaliza, pelo menos na realidade de países desenvolvidos, para ganhos em ambas as partes. A universidade pode angariar investimentos para a pesquisa básica, obter conhecimento industrial e ter a possibilidade de estabelecer oportunidades profissionais para seus alunos (MELO, 2002). As empresas buscam as universidades com foco em novos conhecimentos e para melhorar sua capacidade de competição, buscando pessoas altamente qualificadas nas áreas de atuação que podem, inclusive, oferecer oportunidades para futuros recrutamentos dentro da indústria, resolução de problemas técnicos e redução de custos e riscos envolvidos nos processo de P\&D (BATISTA et al., 2013).

Dados da World Intellectual Property Organization - WIPO (2016, p.19) mostram que o Brasil tem um grande número de publicações e citações acadêmicas, contudo, ainda apresenta um número pequeno de patentes depositadas, quando comparados aos grandes inovadores como Japão, Estados Unidos e Reino Unido bem como a 
países em desenvolvimento como China e Índia. Essa situação resulta na classificação do Brasil como um país ineficiente em inovação.

A importância das universidades para as políticas de inovação, não está só no ensino e na pesquisa, mas estende-se também à proteção legal dos resultados das pesquisas universitárias e sua transposição para valores econômicos. Neste contexto, as patentes mostram-se como um instrumento de proteção efetivo que oferece possibilidades múltiplas para a transferência de conhecimento e tecnologia (HAASE; ARAÚJO; DIAS, 2005).

A patente é um título de propriedade industrial sobre invenção ou modelo de utilidade. O registro de patente garante ao inventor certa segurança nas negociações entre ele e a parte interessada em comprar determinada tecnologia para que possa ser aplicada em algum setor industrial (AMADEI; TORKOMIAN, 2009). No registro de patente deve ser revelado detalhadamente todo o conteúdo técnico do invento, sendo possível para qualquer técnico reproduzi-lo em laboratório. As patentes são depositadas nos institutos responsáveis pela proteção.

Segundo Lopes (1999) "patente ou propriedade intelectual [...] protege a inteligência, a criatividade, o invento, a pesquisa e pressupõe, na sua adoção, uma interação com a comunidade internacional".

\section{Metodologia}

Neste trabalho foram levantadas informações de patente e informações sobre grupos de pesquisa do CNPq para se traçar um perfil de inovação no setor de saúde animal.

As patentes podem ser usadas como meio de se obter o padrão de inovação num dado período de tempo, local e área tecnológica (LEYDESDORFF et al., 2015).

O Conselho Nacional de Desenvolvimento Científico e Tecnológico (CNPq), agência do Ministério da Ciência, Tecnologia, Inovações e Comunicações (MCTIC) tem como principais atribuições fomentar a pesquisa científica e tecnológica e incentivar a formação de pesquisadores brasileiros. O Diretório de Grupos de Pesquisa do CNPq (DGP) reúne informações sobre os grupos de pesquisa que estão em atividade no país, e compreende pesquisadores, estudantes, linhas de pesquisa em andamento e a produção científica, tecnológica gerada pelos grupos de pesquisa. 
Todos os dados levantados neste trabalho compreenderam um período de 10 anos, ou seja, foram consideradas patentes depositadas no período de 2006 a 2016, bem como grupos de pesquisa criados durante este mesmo período.

Para o levantamento das patentes, depositadas no Brasil por indústrias farmacêuticas veterinárias, foram consideradas oito empresas com maior faturamento no país, de acordo com o ranking publicado pelo (BNDES, 2013): Zoetis, Merck/MSD Animal Health, Merial, Ourofino, Valleé, Bayer Animal Health, Elanco Animal Health e Novartis Animal Health. A Elanco, embora não contemplada no ranking nacional de 2013, foi considerada para o levantamento, pois no momento da elaboração deste trabalho já havia feito a aquisição da Novartis Animal Health. Em relação às Universidades foram buscadas patentes depositadas pelas universidades, USP, UNICAMP e UNESP.

A classificação dos dados de patente considerou a Classificação Internacional de Patentes (IPC), a qual é determinada pela World Intellectual Property Organization (WIPO). Nessa classificação, as tecnologias são subdivididas em seção, classe, subclasse e grupo. Para a busca de patentes de interesse para este trabalho, inicialmente, foi feita uma busca mais abrangente pelo nome do depositante (nome da empresa ou universidade), na sequência foram selecionadas as pertencentes às seções de interesse (descritas no Quadro 1) e, então, cada patente foi analisada a fim de sub classificá-las por área de interesse dentro do mercado de saúde animal (Quadro 2).

Quadro 1- Seções e subseções de interesse para a pesquisa.

\begin{tabular}{|c|c|}
\hline SEÇÃO & SUBSEÇÃO \\
\hline A - necessidades humanas & Agricultura; Saúde, salvamento e recreação \\
\hline B - operações de processamentos; transporte & $\begin{array}{c}\text { Separação, mistura; Tecnologia das } \\
\text { microestruturas, nanotecnologia }\end{array}$ \\
\hline C - química metalurgia & Química \\
\hline
\end{tabular}

Fonte: Própria autoria. 
Quadro 2 - Temas de interesse usados para classificação das patentes e grupos de pesquisa.

\begin{tabular}{|c|}
\hline TEMA \\
\hline Aditivo alimentar/ alimentação \\
\hline Anestésico \\
\hline Antimicrobiano \\
\hline Antinflamatório \\
\hline Antiparasitário \\
\hline Biológicos \\
\hline Liberação Controlada \\
\hline Nanotecnologia \\
\hline Outros \\
\hline Reprodução \\
\hline
\end{tabular}

Fonte: Própria autoria.

A busca pelos grupos de pesquisa foi realizada por área de interesse (Quadro 2). Foram levantados grupos no cenário nacional, na região Sudeste e então selecionados apenas aqueles pertencentes às universidades USP, UNESP e UNICAMP. Contudo, os grupos de estudo destas universidades não entraram na análise estatística por apresentarem uma baixa frequência observada (menores do que 5).

As patentes depositadas por empresas farmacêuticas veterinárias foram utilizadas para a visualização do panorama de demandas de inovação (qual caminho está sendo trilhado pelas indústrias desta área). As patentes depositadas por universidades (USP, UNESP e UNICAMP) foram interpretadas a fim de se buscar oportunidades de inovação e parceria vindas do campo acadêmico. Ainda, tentando sinalizar para possíveis oportunidades de inovação, foram levantadas informações sobre grupos de pesquisa usando a base de dados do Diretório de grupos do CNPq. Os dados de patentes, bem como os grupos de pesquisa foram classificados de acordo com as áreas de interesse para saúde animal, e então foram comparados a fim de verificar se Indústria e Universidades caminham juntas, ou não, em termos de inovação tecnológica em saúde animal no Brasil.

Durante a pesquisa bibliográfica para este trabalho não foram encontradas publicações traçando o perfil de interação entre universidades e indústrias (se existe ou não e quais os principais objetivos desta parceria) na área da Medicina Veterinária e no setor farmacêutico veterinário. Em decorrência disso, verificou-se junto ao Diretório de grupos do CNPq a existência ou não de alguma parceria entre 
universidades e empresas privadas a fim de acrescentar informações sobre a interação público-privada neste setor e iniciar possíveis discussões sobre o tema.

Assim, confrontando-se as patentes depositadas pela indústria com as depositadas pelas universidades e com os grupos de pesquisa, foi testada a hipótese que os dois segmentos seguiriam o mesmo perfil de produção científicotecnológica.

Para isso foi empregado método estatístico Qui-Quadrado, o qual permite comparar possíveis divergências entre as frequências observadas e esperadas para certo evento, a fim de verificar o perfil de produção tecnológica realizada pelos dois segmentos: universidade e indústria farmacêutica veterinária. Assim, assumiu-se que dois grupos teriam comportamentos semelhantes quando a diferença entre a frequência observada e esperada em cada categoria fosse próxima a zero. Classificações que tiveram frequência de observação inferior a 01 (um) foram agrupadas na classificação "outros", para possibilitar o cálculo estatístico.

$\mathrm{Na}$ categoria "outros", além das categorias com frequência inferior a um, foram compreendidos grupos de pesquisa e patentes nos temas: antineoplásicos, antialérgicos, kits para diagnóstico, marcadores moleculares, produtos dermatológicos, cicatrizantes e antifúngicos. Essa classificação foi usada para padronizar os temas analisados.

\section{Resultados}

No total, foram encontradas 1.458 patentes depositadas no INPI, no período de 2006 a 2016, somando-se o total depositado por indústrias de saúde animal e pelas universidades USP, UNESP e UNICAMP. Muitas patentes não puderam ser classificadas por ainda estarem sob sigilo. Para as demais, 369 foram classificas nos temas propostos, após aplicado o filtro pelas classificações de interesse (Quadros 1 e 2). Das 369 patentes encontradas, $52,85 \%$ (195) foram depositados pelas indústrias farmacêuticas e $46,34 \%$ pelas universidades pesquisadas (Tabela 1). 
Tabela 1 - Dados gerais: número de patentes depositadas por empresas e universidades, número de grupos de pesquisas no Brasil, no Sudeste e nas universidades UNESP, USP e UNICAMP, entre 2006 a 2016.

\begin{tabular}{cccccccc}
\hline & \multicolumn{2}{c}{ Patentes (2006 a 2016) } & \multicolumn{3}{c}{ Grupos de Pesquisa CNPq (2006 a 2016) } \\
\cline { 2 - 7 } Classificação & $\begin{array}{c}\text { Indústria } \\
\text { Saúde } \\
\text { Animal }\end{array}$ & Universidades & Brasil & Sudeste & UNESP & UNICAMP & USP \\
\hline Antimicrobiano & 22 & 15 & 81 & 33 & 3 & 3 & 0 \\
Antiparasitário & 69 & 12 & 13 & 2 & 0 & 0 & 0 \\
Biológico & 61 & 30 & 65 & 9 & 2 & 0 & 2 \\
Liberação & 8 & 7 & 30 & 43 & 0 & 0 & 0 \\
Controlada & 35 & 110 & 543 & 148 & 15 & 4 & 4 \\
Outros & 195 & 174 & 732 & 235 & 20 & 7 & 6 \\
\hline Total & & & & & & & \\
\hline Fonte: Própria autoria. & & &
\end{tabular}

Das patentes depositadas pelas indústrias de saúde animal, observou-se que as relacionadas a desenvolvimento de antiparasitários e produtos biológicos tiveram os maiores percentuais de depósito, sendo 35,38\% e 31,28\%, respectivamente. $\mathrm{Na}$ sequência verificou-se que $17,95 \%$ de patentes foram classificadas como "outros", $11,28 \%$ como antimicrobiano e 4,10\% como desenvolvimentos de formulações de liberação controlada.

Por parte das universidades, 63,22\% das patentes foram classificadas como "outros", o que mostra que diversas pesquisas estão sendo realizadas nas áreas de tratamentos antineoplásicos, medicamentos antialérgicos, desenvolvimento de kits diagnóstico, marcadores moleculares, produtos dermatológicos, cicatrizantes e antifúngicos. Ainda, $17,24 \%$ das patentes descreviam tecnologias para produtos biológicos, 8,62\% produtos antimicrobianos, 6,90\% antiparasitários e 4,02\% como tecnologias para o desenvolvimento de formulações de liberação controlada.

Em âmbito nacional foram encontrados 732 grupos de pesquisa ativos no banco de dados do Diretório de Grupos do CNPq (Tabela 1). Destes, 74,18\% foram classificados como "outros". Nesta categoria foram incluídos os temas nutrição animal, anestésicos, anti-inflamatórios, fitoterápicos, nanotecnologia e reprodução, por isso se observou alto percentual de grupos nessa categoria. Ainda, dos grupos pesquisados, $11,06 \%$ foram classificados como antimicrobianos, 8,88\% como grupos de estudo na área de biológicos, 4,10\% como liberação controlada e 1,78\% como antiparasitários. 
A análise estatística das patentes revelou diferença significativa $(p=0,001)$ entre as diferentes classificações de patentes depositadas pelos dois atores do segmento avaliado, indicando perfis diferentes de produção tecnológica e científica entre universidades e empresas no período estudado (2006 a 2016) (Tabela 2). Contudo, é possível observar que a frequência observada de patentes relacionadas a novas tecnologias antimicrobianas e de formulações de liberação controlada foram semelhantes entre indústrias e universidades, demonstrando que essas áreas podem representar uma potencial possibilidade de colaboração entre universidade e empresa.

A comparação entre grupos de pesquisa e as patentes depositadas pelas empresas de saúde também apontou perfil distinto de inovação entre os dois setores ( $p=0,001)$ (Tabela 3). E, assim como na comparação das patentes depositadas por indústrias e universidades, dois temas tiveram perfis semelhantes em relação ao todo: antimicrobianos e desenvolvimentos de formulações de liberação controlada.

Tabela 2 - Número e percentual de patentes depositadas pelas indústrias de saúde animal e universidades no Brasil, no período entre 2006 e 2016.

\begin{tabular}{|c|c|c|c|c|}
\hline Classificação & Frequências & Indústrias de Saúde Animal & Universidades & Total \\
\hline \multirow{2}{*}{ Antimicrobianos } & observada & $22(11,28 \%)$ & $15(8,62 \%)$ & 37 \\
\hline & esperada & 19.55 & 17,45 & \\
\hline \multirow{2}{*}{ Antiparasitários } & observada & $69(35,38 \%)$ & $12(6,90 \%)$ & 81 \\
\hline & esperada & 42,8 & 17,96 & \\
\hline \multirow{2}{*}{ Biológicos } & observada & $61(31,28 \%)$ & $30(17,24 \%)$ & 91 \\
\hline & esperada & 48,09 & 42,91 & \\
\hline \multirow{2}{*}{ Liberação Controlada } & observada & $8(4,10 \%)$ & $7(4,02 \%)$ & 15 \\
\hline & esperada & 7,93 & 7,07 & \\
\hline \multirow{2}{*}{ Outros } & observada & 35 (17,95\%) & $110(63,22 \%)$ & 145 \\
\hline & esperada & 76,63 & 68,37 & \\
\hline Total & & 195 & 174 & 369 \\
\hline
\end{tabular}

Qui-Quadrado de Pearson = 89,952; $G L=4 ; p=0,001$

Qui-Quadrado da Razão de Verossimilhança $=96,052 ; G L=4, p=0,001$

Fonte: Própria autoria. 
Tabela 3 - Número e percentual de patentes depositadas pelas indústrias de saúde animal e grupos de pesquisa nacionais ativos (Diretório de Grupos do CNPq), no período entre 2006 e 2016.

\begin{tabular}{ccccc}
\hline Classificação & Frequências & $\begin{array}{c}\text { Indústrias de Saúde } \\
\text { Animal }\end{array}$ & $\begin{array}{c}\text { Grupos de Pesquisa } \\
\text { (Brasil) }\end{array}$ & Total \\
\hline Antimicrobianos & observada & $22(11,28 \%)$ & $81(11,06 \%)$ & 103 \\
& esperada & 21,67 & 81,33 & 82 \\
\hline Antiparasitários & observada & $69(35,38 \%)$ & $13(1,78 \%)$ & 126 \\
& esperada & 17,25 & 64,75 & 38 \\
\hline Biológicos & observada & $61(31,28 \%)$ & $65(8,88 \%)$ & \\
\hline Liberação Controlada & esperada & 26,5 & $30(4,10 \%)$ & 378 \\
& observada & $8(4,10 \%)$ & 30,01 & 927 \\
\hline Outros & esperada & 7,99 & $543(74,18 \%)$ & 456,41 \\
\hline
\end{tabular}

Qui-Quadrado de Pearson = 331,570; $G L=4 ; p=0,001$

Qui-Quadrado da Razão de Verossimilhança $=297,403 ; G L=4, p=0,001$

Fonte: Própria autoria.

Quando foram considerados os grupos pertencentes às universidades da região Sudeste, 235 grupos de pesquisa foram expostos $(32,10 \%$ do total de 732 grupos ativos no CNPq). Destes grupos, 62,98\% foram classificados como "outros". O alto percentual nesta categoria se dá pela junção de temas conforme explicado anteriormente, 18,29\% como liberação controlada, 14,04\% como antimicrobianos, 3,83\% como biológicos e 0,85\% como antiparasitários. A análise estatística também revelou, neste caso, diferença significativa entre as diferentes classificações dos temas de interesse quando comparados aos grupos de pesquisa da região Sudeste e as patentes depositadas pelas indústrias ( $p=0,001)$ (Tabela 4), ou seja, não ocorre mesmo perfil ou frequência de patentes e grupos de pesquisa nas categorias estudadas. Esta comparação revelou semelhança apenas nas produções tecnológicas e científicas relacionadas ao desenvolvimento de antimicrobianos. 
Tabela 4 - Número e percentual de patentes depositadas pelas indústrias de saúde animal e grupos de pesquisa ativos das universidades do Sudeste (Diretório de Grupos do CNPq), no período entre 2006 e 2016.

\begin{tabular}{ccccc}
\hline Classificação & Frequências & $\begin{array}{c}\text { Indústrias de Saúde } \\
\text { Animal }\end{array}$ & $\begin{array}{c}\text { Grupos de Pesquisa } \\
\text { (Sudeste) }\end{array}$ & Total \\
\hline Antimicrobianos & observada & $22(11,28 \%)$ & $33(14,04 \%)$ & 55 \\
& esperada & 24,94 & 30,06 & 71 \\
\hline Antiparasitários & observada & $69(35,38 \%)$ & $2(0,85 \%)$ & 70 \\
& esperada & 32,2 & 38,8 & 51 \\
\hline Biológicos & observada & $61(31,28 \%)$ & $38,26 \%)$ & 183 \\
& esperada & 31,74 & $43(18,29 \%)$ & \\
\hline Liberação Controlada & observada & $8(4,10 \%)$ & $148(62,98 \%)$ & 100,01 \\
& esperada & 23,13 & 235 & 430 \\
\hline Outros & observada & $35(17,95 \%)$ & & \\
\hline
\end{tabular}

Qui-Quadrado de Pearson = 195,823; $G L=4 ; p=0,001$

Qui-Quadrado da Razão de Verossimilhança $=223,480 ; G L=4, p=0,001$

Fonte: Própria autoria.

Dos grupos de pesquisa situados na região Sudeste, foram avaliados ainda aqueles pertencentes às universidades USP, UNESP e UNICAMP, totalizando 33 grupos de estudo. Contudo, o baixo número de grupos encontrados e frequências de pesquisas menores do que um em determinadas classificações não permitiram comparações estatísticas destes resultados. Mesmo assim, foram observadas frequências maiores de grupos classificados como "outros" nas três universidades. As áreas de antimicrobianos e biológicos tiveram observações nas universidades UNESP e UNICAMP. Esses achados caracterizam perfil semelhante ao observado para os grupos de pesquisa no cenário nacional e da região sudeste.

$\mathrm{Na}$ busca por interações público-privadas junto ao diretório de grupos do CNPq verificou-se que, dos 732 grupos encontrados, 64 citam parceria com empresas privadas, o que representa menos de $10 \%$ do total. Ainda, verificou-se que nos grupos de pesquisa da região Sudeste não foram informadas parcerias com empresas. Segundo Rapini, Oliveira e Caliari (2016) embora as informações na plataforma do Diretório de Grupos do CNPq seja de preenchimento opcional, seu universo abrangido vem aumentando ao longo dos anos, podendo-se supor relativa representatividade da comunidade científica nacional. 


\section{Discussão}

Pelos dados de patentes foi possível verificar um perfil positivo de inovação das indústrias farmacêuticas veterinárias, o que pode ser usado como um guia de possíveis demandas e oportunidades de parcerias público-privadas. O maior número de patentes depositadas por empresas do setor de saúde animal no Brasil, nas áreas de antiparasitário e produtos biológicos, corrobora com os dados do (SINDAN, 2015). Este informa que no Brasil, $50 \%$ do faturamento da indústria de saúde animal, em 2015, foi obtido com a venda de produtos biológicos e antiparasitários. Este maior faturamento nestas áreas pode ser justificado por dois principais fatores. $O$ primeiro é relacionado às campanhas de vacinação implementadas pelo Ministério da Agricultura, Pecuária e Abastecimento (CAPANEMA et al., 2007). O serviço veterinário brasileiro é responsável pela execução das políticas de saúde animal, e compartilha com o setor privado as responsabilidades nos seguintes programas nacionais: Programa Nacional de Erradicação e Prevenção de Febre Aftosa (PNEFA), Programa Nacional de Controle de Raiva dos Herbívoros (PNCRG) e Programa Nacional de Controle e Erradicação da Brucelose e Tuberculose Animal (PNCEBT) (SALANI, 2015). O segundo fator se dá no fato do Brasil possuir um dos maiores rebanhos bovinos, espécie animal que demanda o uso de antiparasitários em decorrência da redução de produtividade e aumentos das susceptibilidades a outras doenças nos animais parasitados. Grisi et al. (2014) estimaram um prejuízo na bovinocultura brasileira de U\$14,0 milhões em decorrência do parasitismo.

Os dados de patente encontrados seguem o perfil global de inovação da área de saúde animal. Segundo matéria publicada por Nicholas (2017), no site do Animal Pharm, quase dois terços dos novos pedidos de patentes em 2016 descreveram inovações em antiparasitários e vacinas, refletindo a importância desses dois grupos de produtos no mercado global de saúde animal. No cenário mundial, de 131 novas patentes depositadas, 43 foram relacionadas a antiparasitários sendo 20 referentes às novas moléculas e 17 descrevendo novas formulações ou combinações de antiparasitários existentes. As vacinas e demais produtos biológicos foram responsáveis por mais 40 novos pedidos de patentes.

Para as universidades pesquisadas (USP, UNESP e UNICAMP) foi verificado número expressivo de patentes depositadas no período estudado (2006 a 2016). Além disso, a quantidade de depósitos foi semelhante à encontrada neste trabalho 
para o setor privado (indústria de saúde animal), mostrando que o setor acadêmico está dando importância à ciência aplicada e para a propriedade intelectual. O perfil de patentes depositadas não segue o mesmo verificado para as empresas. Os depósitos se concentraram na área de produtos biológicos e dentro da categoria "outros".

Neste trabalho, foram consideradas todas as patentes com potencial relacionamento com o setor de saúde animal e, dessa forma, considerou-se também patentes no âmbito de saúde humana, o que pode ter influenciado o perfil de patentes depositadas pelas universidades. Pelo fato das indústrias da saúde animal e humana compartilhar produtos e tecnologias em seus portfólios (AHMED; KASRAIAN, 2002; CAPANEMA et al., 2007), a não exclusão das patentes de saúde humana se justifica. Além disso, não foi objetivo deste trabalho fazer o estudo aprofundado das tecnologias encontradas, necessário para julgar, em um primeiro momento, se dada tecnologia pode ser aproveitada por um mercado ou outro.

Verificou-se durante a execução deste trabalho que as patentes provenientes das universidades são divulgadas pelos núcleos de inovação tecnológica de tais universidades (Agência USP de Inovação - AUSPIN, Agência de Inovação da Unicamp - Inova Unicamp e a Agência UNESP de Inovação - AUIN), abrindo a porta de comunicação entre estas e o setor industrial. Dentro do site da AUSPIN, por exemplo, no campo "Projetos Vigentes" é possível ter acesso à demandas específicas de empresas como a Eli Lilly and Company (detentora da Elanco Saúde Animal) e Bayer Saúde Animal. Durante o levantamento de dados deste trabalho foi observado que as agências de inovação, além de promoverem a comunicação entre setores, também disponibilizam material informativo referente à proteção e à transferência de tecnologia, auxiliando assim no maior conhecimento deste assunto.

Neste sentido, a Lei de Inovação de 2004 (BRASIL, 2004) trouxe como uma exigência a criação dos Núcleos de Inovação Tecnológica dentro dos Institutos de Ciência e Tecnologia (incluindo universidades) o que estimulou a adoção de políticas de incentivo e cultura de inovação pelas universidades. As agências de inovação desempenham papel estratégico na gestão do conhecimento produzido dentro da universidade tendo papel importante na relação universidade-empresa (CASTRO; SOUZA, 2012).

A comparação entre patentes do setor privado e os grupos de pesquisa do CNPq também revelou perfil distinto de produção científico-tecnológica, com exceção das 
áreas de antimicrobianos e formulações de liberação controlada. Contudo, foram considerados todos os grupos de pesquisa com potencial relacionamento com 0 setor de saúde animal e, dessa forma, considerou-se também grupos no âmbito de saúde humana o que pode ter influenciado o perfil verificado nas universidades. $O$ intuito deste estudo foi levantar o maior número de possíveis oportunidades de inovação e parcerias e, dessa forma, a pesquisa foi mais abrangente. Diante do grande número de grupos de pesquisa nas diferentes áreas, verifica-se que existem potenciais oportunidades de inovação no meio acadêmico, o que reforça a importância das universidades e da interação entre os dois campos, indústria e universidade, para a inovação no Brasil.

Pereira et al. (2009) destacam que, em países como Japão, EUA, Canadá, Inglaterra e Alemanha, a transferência de tecnologia já é uma prática consolidada. De uma forma geral, nos países latino-americanos, a colaboração entre universidades e empresas é uma interação recente, mas começou a se fazer presente como forma de superar os desafios da produtividade e da competitividade.

Neste trabalho, foram observados poucos grupos traçando parcerias com empresas privadas, menos de $10 \%$ dos grupos estudados. Em trabalho menos recente, Rapini e Righi (2007) encontraram 8,4\% de grupos de pesquisa do CNPq com algum tipo de relacionamento com empresas em 2002 e 11,05\% em 2004, caracterizando assim um aumento na interação público-privada neste período. Ainda, Rapini e Righi (2007), observaram aumento dessa interação nas grandes áreas Ciência da Saúde e Ciências Exatas e da Terra. Nascimento (2011) ressalta em seu trabalho que a interação universidade-empresa cria um fluxo de conhecimento que promove crescimento coordenado de ambas as partes, além do alinhamento de interesses o que favorece um sistema inovativo mais eficiente. $\mathrm{Na}$ análise do relacionamento existente entre grupos de pesquisa do CNPq e empresas, o autor destaca a necessidade de maior proximidade entre empresas e universidades de modo que as universidades possam ampliar suas atividades e contribuir para o desenvolvimento tecnológico, sem deixar de lado a ciência básica, e que as empresas se usufruam dessa interação no sentido de complementar seu desenvolvimento tecnológico, serviços de consultoria e maior proximidade com o capital humano para posterior recrutamento.

Berni et al. (2015), por meio de entrevistas, também evidenciaram benefícios na interação universidade-empresa. Os autores descrevem como benefícios citados 
pelas empresas entrevistadas o auxílio no desenvolvimento de novos processos e produtos/inovação e para as universidades o auxílio na formação de profissionais, possibilidades de direcionamento dos estudos para aplicações práticas e maior interatividade com a comunidade.

Dentro do setor de saúde animal, especificamente, não foram encontrados trabalhos publicados estudando esta interação universidade-empresa, o que mostra a importância de mais estudos nessa área a fim de permitir a visualização das possíveis lacunas existentes entre esses dois setores e possibilitar a sugestão de modelos para aproximá-los e estimular a interação. O Brasil ainda é considerado um país ineficiente em inovação (WIPO, 2016) e essa maior aproximação, aliada a outras medidas, se faz necessária para estimular o processo de inovação.

A interação universidade-empresa existe no Brasil, porém não ocorre de forma espontânea e precisa ser estimulada. Neste sentido, Paranhos e Hasenclever (2013) destacam, no contexto da indústria farmacêutica humana, cinco pontos chave para estimular a relação universidade-empresa: 1) fortalecimento da estrutura de P\&D nas empresas farmacêuticas; 2) necessidade de reestruturação e modernização da estrutura interna das universidades; 3) necessidade de planejamento prévio das ações do governo e da criação de um ambiente propício para a inovação; 4) o papel essencial desempenhado pelo financiamento do governo e apoio às atividades inovadoras das empresas e para os Núcleos de Inovação Tecnológica (NITs) das universidades; e 5) a necessidade de regulação e regulamentação eficiente do setor farmacêutico.

No âmbito do Estado, novas regulamentações vêm sendo publicadas. Em 2015, foi publicada a Emenda Constitucional 85/2015 (BRASIL, 2015) que, entre outros fatores, introduz, como obrigação dos governos federal, estaduais e municipais, o investimento em ciência e tecnologia, reforçando assim o papel do Estado no processo de inovação; também favorece a subvenção econômica e isenção de tributos nas transações envolvendo ciência, tecnologia e inovação. Neste mesmo ano, foi publicada a Lei 13.204/15 (BRASIL, 2015), que introduz os termos fomento, cooperação e acordo de cooperação, reduz a exigência dos planos de trabalho e passa a exigir maior formalismo nas relações com instituições públicas. No ano de 2016, a Lei 13.243 publicada em 11 de janeiro (BRASIL, 2016), aparentemente traz maiores estímulos ao processo de inovação. Nela há a redução de impostos federais para importações, a dispensa de licitação é estendida para as Instituições Científica, 
Tecnológica e de Inovação (ICTs), reforça a possibilidade de Núcleos de Inovação Tecnológica (NITs) para clusters de ICTs, cria bolsas para inovação, permite o uso de laboratórios e instalações pelos parceiros das ICTs e exige maior segurança nas relações entre empresas e instituições públicas. Assim, num primeiro momento, essas leis pedem maior regulamentação no relacionamento público-privado e dão estímulos para essa interação ocorrer. Em 2016, a Portaria nำ270/16 (SÃO PAULO, 2016) reforçou a operação dos NITs na Agência Paulista de Tecnologia dos Agronegócios (APTA) e o ganho econômico dos pesquisadores científicos em inovações.

O Ministério da Agricultura Pecuária e Abastecimento, órgão que regula o registro de produtos veterinários no Brasil, também está se posicionando sobre o assunto da inovação. Dentre as propostas estão um regulamento para priorizar a análise de produtos considerados inovadores, bem como a implementação de um sistema eletrônico para análise das submissões de registro de produtos. Tais medidas visam diminuir a burocracia regulatória e otimizar o processo de registro de novos produtos (HARVEY, 2016). O lançamento de regulamentações por parte do Estado mostra preocupação deste em melhorar as vias para que as parcerias aconteçam.

Ainda, em relação às medidas nacionais, o Brasil apresentou um aumento no dispêndio em ciência e tecnologia (C\&T), sendo que em 2013 o investimento foi de $\mathrm{R} \$ 85,6$ bilhões (equivalente a 1,66\% do Produto Interno Bruto - PIB). Em 2012 esse investimento foi de 76,4 bilhões (1,62\% do PIB). Parte dos recursos investidos se dá no financiamento de programas de pós-graduação (47\%). Os outros dispêndios contemplam as bolsas do Conselho Nacional de Desenvolvimento Científico e Tecnológico (CNPq/MCTI), da Coordenação de Aperfeiçoamento de Pessoal de Nível Superior (Capes/MEC) e das fundações de amparo à pesquisa (FAPs) e investimentos vinculados a instituições científicas e tecnológicas (ICTs) públicas como a Empresa Brasileira de Pesquisa Agropecuária (Embrapa) e a Fiocruz (BRASIL, 2015).

\section{Considerações finais}

A classificação das patentes depositadas pelas indústrias de saúde animal no Brasil permitiu verificar o perfil de inovação pela classificação das tecnologias 
patenteadas. O mesmo foi traçado para as universidades públicas do estado de São Paulo (USP, UNESP e UNICAMP). De uma forma geral, os dois setores tem perfis distintos, sendo que o setor privado concentra maior número de patentes nas áreas de produtos biológicos e antiparasitários. Enquanto as universidades têm patentes distribuídas em áreas diversas classificadas neste trabalho como "outros", que inclui produtos para reprodução, drogas antineoplásicas, fitoterápicos, antinflamatórios, entre outros.

A investigação da base de dados do Diretório dos Grupos de Pesquisa do CNPq revelou número expressivo de grupos de pesquisa em áreas de interesse para a saúde animal, fornecendo informações quanto às oportunidades de inovação advindas das universidades tanto no cenário nacional quanto da região Sudeste. Também foi possível verificar, brevemente, algumas evidências da articulação recente entre universidades e empresas no país, nos setores com potencial relacionamento com o tema saúde animal.

Nenhum estudo anterior foi encontrado fazendo esta busca no setor de saúde animal, que possui um mercado em expansão e diversas oportunidades de inovação. Espera-se que estes resultados possam facilitar a visualização dessas oportunidades e de possibilidades de parcerias público-privadas.

Esta dissertação foi a primeira iniciativa de se estudar a interação empresauniversidade no setor de saúde animal e outros estudos são necessários para aprofundar o tema e apontar as tendências dessa relação bem como possíveis pontos de melhoria e modelos para melhor condução das parcerias.

\section{Referências}

AGÊNCIA USP DE INOVAÇÃO - AUSPIN. Projetos vigentes. Disponível em: <http://inovacao.usp.br/projetos-vigentes/>. Acesso em: 18 dez. 2016.

AHMED, I.; KASRAIAN, K. Pharmaceutical challenges in veterinary product development. Advanced Drug Reviews, Amsterdam, v. 54, p. 871-882, 2002.

AMADEI, J. R. P.; TORKOMIAN, A. L. V. As patentes nas universidades: análise dos depósitos das universidades públicas paulistas. Ciência da Informação, Brasília, v. 38, p. 9-18, 2009.

BANCO NACIONAL DE DESENVOLVIMENTO ECONÔMICO E SOCIAL - BNDES. Informe Setorial: área industrial, Brasília, n. 27, p.1-6, nov. 2013. 
BATISTA, P. C. S. et al. Relações governo-universidade-empresa para a inovação tecnológica. AOS - Amazônia, Organizações e Sustentabilidade, Amazônia, v. 2, p. 7-21. 2013.

BERNI, J. C. A. et al. Interação universidade-empresa para a inovação e transferência de tecnologia. Revista GUAL, Florianópolis, v. 8, p. 258-277, 2015.

BRASIL. Lei 10.973, de 02 de dezembro de 2004. Dispõe sobre incentivos à inovação e à pesquisa científica e tecnológica no ambiente produtivo e dá outras providências. Diário Oficial [da] União, Brasília, DF, 16 maio 2005. Disponível em:<http://www.planalto.gov.br/ccivil_03/_ato2004-2006/2004/Lei/L10.973.htm>. Acesso em: 04 mar. 2016.

BRASIL. Emenda Constitucional n 85, de 26 de fevereiro de 2015. Altera e adiciona dispositivos na Constituição Federal para atualizar o tratamento das atividades de ciência, tecnologia e inovação. Diário Oficial [da] União, Brasília, DF, 27 fev. 2015. Disponível em:

<http://www.planalto.gov.br/ccivil_03/Constituicao/Emendas/Emc/emc85.htm>. Acesso em: 07 nov. 2016.

BRASIL. Lei no 13.204, de 14 de dezembro de 2015. Altera a Lei no 13.019, de 31 de julho de 2014. Diário Oficial [da] União, Brasília, DF, 15 dez. 2015. Disponível em: <http://www.planalto.gov.br/ccivil_03/_Ato2015-2018/2015/Lei/L13204.htm>. Acesso em: 08 nov. 2016.

BRASIL. Lei no 13.243, de 11 de janeiro de 2016. Dispões sobre estímulos ao desenvolvimento científico, à pesquisa, à capacitação científica e tecnológica e à inovação. Diário Oficial [da] União, Brasília, DF, 12 jan. 2016. Disponível em: <http://www.planalto.gov.br/ccivil_03/_ato2015-2018/2016/lei/l13243.htm>. Acesso em: 08 nov. 2016.

BRASIL. Ministério da Ciência, Tecnologia e Inovação - MCTI. Aumenta o investimento em C\&T no Brasil. 2015. Disponível em:<http://www.mcti.gov.br/noticia//asset_publisher/epbV0pr6elS0/content/aumenta-o-investimento-em-c-t-nobrasil;jsessionid=C3463D046E6AA348237F66107BBBB77E>. Acesso em: 05 nov. 2016.

CAPANEMA, L. X. L. et al. Panorama da indústria farmacêutica veterinária. BNDES, Rio de Janeiro: BNDES Setorial, v. 25, p. 157-174, 2007.

CAPANEMA, L. X. L., PALMEIRA-FILHO, P. L. Indústria farmacêutica brasileira: reflexões sobre sua estrutura e potencial de investimentos. Rio de Janeiro: BNDES, 2007. 44 p.

CASTRO, B. S.; SOUZA, G. C. O papel dos núcleos de inovação tecnológica (NITs) nas universidades brasileiras. Liinc em Revista, Rio de Janeiro, v. 8, p. 125-140, 2012. 
CRUZ, L. B.; PEDROZO, E. A. Inovação tecnológica e vantagem competitiva no setor de telefonia móvel brasileiro: estudos de caso em filiais no Rio Grande do Sul. RAC-Eletrônica, Rio de Janeiro, v. 2, n. 1, p. 1-19, 2008.

GONÇALO, C. R.; ZANLUCHI, J. Relacionamento entre empresa e universidade: uma análise das características de cooperação em um setor intensivo em conhecimento. Base - Revista de Administração e Contabilidade Unisinos, São Leopoldo, v. 8, n. 3, p. 261-272, 2011.

GRISI, L. et al. Reassessment of the potential economic impact of cattle parasites in Brazil. Revista Brasileira de Parasitologia Veterinária, São Paulo, v. 23, n. 2, p. 150-156, 2014.

HAASE, H.; ARAÚJO, E. C.; DIAS, J. Inovações vistas pelas patentes: exigência frente às novas funções das Universidades. Revista Brasileira de Inovação, Campinas, v. 4, n. 2, p. 329-362, 2005. Disponível em: <http://ocs.ige.unicamp.br/ojs/rbi/article/view/290/206>. Acesso em: 10 dez. 2016.

HARVEY, J. Brazil aims to reduce its excessive regulatory bureaucracy. Animal Pharm, 2016. Disponível em:<https://www.agra-net.com/agra/animalpharm/regions/brazil/brazil-aims-to-reduce-its-excessive-regulatory-bureaucracy534244.htm>. Acesso em: 10 fev. 2017.

KAMIMURA, Q. P.; CORNETTA, V. K. Inovação e propriedade intelectual no setor farmacêutico: desafios governamentais e efeitos na saúde pública. In: ENCONTRO NACIONAL DE ENGENHARIA DE PRODUÇÃO, 31., 2011, Belo Horizonte. Anais eletrônicos... Belo Horizonte, 2011. Disponível em:

<http://www.abepro.org.br/biblioteca/enegep2011_TN_STO_135_855_18348.pdf>. Acesso em: 10 dez. 2016.

LEYDESDORFF, L. et al. Patents as instruments for exploring innovation dynamics: geographic and technological perspectives on "photovoltaic cells". Scientometrics, Budapest, v. 102, p. 629-551, 2015.

LOPES, N. P\&D propriedade intelectual e comercialização da tecnologia. In: ENCONTRO DA PROPRIEDADE INTELECTUAL E COMERCIALIZAÇÃO DA TECNOLOGIA, 2., 1999, Rio de Janeiro. Anais... Rio de Janeiro: Rede de Tecnologia do Rio de Janeiro, 1999. 100 p.

MELO, P. A. A cooperação universidade/empresa nas universidades públicas brasileiras. 2002. 330 p. Tese (Doutorado) - Universidade Federal de Santa Catarina, Florianópolis, 2002.

NASCIMENTO, F. L. A importância da interação universidade-empresa no processo inovativo. 2011. 58 p. Instituto de Economia, Universidade Estadual de Campinas, Campinas, 2011. Disponível em: $<$ www.bibliotecadigital.unicamp.br/document/?down=000852575>. Acesso em: 10 nov. 2016. 
ORGANIZAÇÃO PARA COOPERAÇÃO ECONÔMICA E DESENVOLVIMENTO OECD. Manual de Oslo: diretrizes para coleta e interpretação de dados sobre inovação. 3. ed. Rio de Janeiro: FINEP, 2005.

NICHOLAS, R. Review 2016: patenting strategies focus on antiparasitics and vacines". Animal Pharm. 2017. Disponível em:<https://www.agra-

net.com/agra/animal-pharm/analysis/review-2016-patenting-strategies-focus-onantiparasitics-and-vaccines-541574.htm>. Acesso em: 10 fev. 2017.

PARANHOS, J.; HASENCLEVER, L. O sistema farmacêutico de inovação e o relacionamento empresa-universidade no setor farmacêutico do Estado do Rio de Janeiro. Cadernos do Desenvolvimento Fluminense, Rio de Janeiro, v. 2, p. 81103, 2013.

PEREIRA, M. F. et al. Transferência de conhecimentos científicos e tecnológicos da universidade para o segmento empresarial. Revista de Administração e Inovação, São Paulo, v. 6, n. 3, p. 128-144, 2009.

RAPINI, M. S.; RIGHI, H. M. Interação universidade-empresa no Brasil em 2002 e 2004: uma aproximação a partir dos grupos de pesquisa do CNPq. Revista Economia, Rio de Janeiro, v. 8, n. 2, p. 248-268, 2007.

RAPINI, M. C.; OLIVEIRA, V. P.; CALIARI, T. Como a interação universidadeempresa é remunerada no Brasil: evidências dos grupos de pesquisa do CNPq. Revista Brasileira de Inovação, São Paulo, v. 15, n. 2, p. 219-246, 2016. Disponível em:<http://ocs.ige.unicamp.br/ojs/rbi/article/view/1315>. Acesso em: 10 fev. 2017.

RATTNER, H. Inovação tecnológica e pequenas empresas: uma questão de sobrevivência. Revista de Administração de Empresas, Rio de Janeiro, v. 24, n. 3, p. 70-73, 1984.

SALANI, E. C. Relevância da sanidade animal. Agoranalysis, Rio de janeiro, Conteúdo Especial - Pecuária Brasileira. 2015. Disponível em: <http://www.agroanalysis.com.br/11/2015/conteudo-especial/pecuaria-brasileiramercado-ajustado>. Acesso em: 06 fev. 2017.

SANTOS, M. C. B. G.; PINHO, M. Estratégias tecnológicas em transformação: um estudo da indústria farmacêutica brasileira. Revista Gestão e Produção, São Carlos, v. 19 , n. 2, p. 405-408.

SÃO PAULO (Estado). Agência Paulista de Tecnologia dos Agronegócios. Portaria no 270 de 28 de junho de 2016. Diário Oficial, Poder Executivo, São Paulo, 29 jun. 2016. Seção I, p. 126(119)-25. Disponível em:

<https://www.imprensaoficial.com.br/DO/GatewayPDF.aspx?link=/2016/executivo\%2 0secao\%20i/junho/29/pag_0025_87QIIGJ206512e3R5MMKGS37NEC.pdf>. Acesso em: 07 nov. 2016. 
SINDICATO NACIONAL DA INDÚSTRIA DE PRODUTOS PARA SAÚDE ANIMA SINDAN. Mercado. 2015.Disponível em:

<http://www.sindan.org.br/sd/base.aspx?controle=8>. Acesso em: 12 jan. 2015.

WORLD INTELECTUAL PROPERTY ORGANIZATION - WIPO. The global innovation index 2016. Winning with Global Innovation. 2016. cap. 1, p. 19.

Disponível em:<https://www.globalinnovationindex.org/>. Acesso em: 20 out. 2016.

YAMAGUISHI, S. H. Gestão da inovação na indústria farmacêutica no Brasil: estudo de múltiplos casos. 2014. 225 p. Tese (Doutorado) - Instituto de Pesquisas Energéticas e Nucleares, Universidade de São Paulo, São Paulo, 2014. 
ANEXOS 
ANEXO A - Comprovante de envio para análise.

CFMV - Revista CFMV

Trabalhos

ID: 221/2017 Data de Envio: 20/02/2017

Título: Inovação Farmacêutica Veterinária no Brasil

Autores: Carolina Cive Barbosa /Celso da Costa Carrer / Vera Letticie de Azevedo Ruiz

Situação: Recebido, em análise do editor 
ANEXO B - Comprovante de envio para análise.

\section{(巛) R E V IS T A E L E T R Ô N I C A D E}

\section{A D M I N I S T R A Ç Ã O}

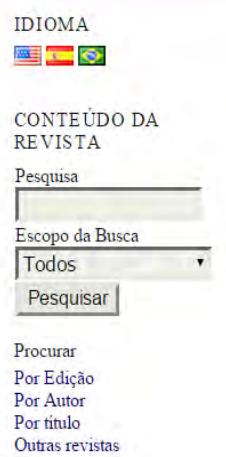

PALAVRAS-CHAVE

Competitividade

Comnortamento do

CAPA SOBRE PÁGINA DO USUÁRIO PESQUISA ATUAL
ANTERIORES NOTÍCIAS EA/UFRG UFRGS
\[ \text { Capa }>\text { Usuário }>\text { Autor }>\text { Submissões Ativas } \]

SUBMISSÕES ATIVAS

\begin{tabular}{|c|c|c|c|c|c|}
\hline ATIVO & ARQUIVO & & & & \\
\hline ID & $\begin{array}{l}\text { MM-DD } \\
\text { ENVIADO }\end{array}$ & SEÇÃO & AUTORES & TÍTULO & SITUAÇÃ \\
\hline 74353 & $23-06$ & ART & $\begin{array}{l}\text { Cive } \\
\text { Barbosa, } \\
\text { da Costa } \\
\text { Carrer,... }\end{array}$ & $\begin{array}{l}\text { ANÁLISE DA } \\
\text { INTERACCÃO ENTRE } \\
\text { A INDUSTRIA } \\
\text { FARMACÉUTICA... }\end{array}$ & $\begin{array}{r}\text { Aguardando } \\
\text { designação }\end{array}$ \\
\hline
\end{tabular}

1 a 1 de 1 itens

INICIAR NOVA SUBMISSÃO
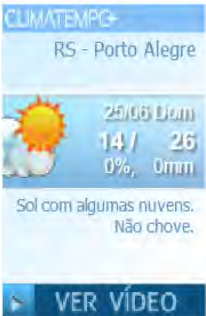

LINKS INTERESSANTES

INDEXADORES, CATÁLOGOS E OUTROS 